\title{
Competencias en materia de aguas de las Comunidades Autónomas que pertenecen a cuencas intercomunitarias (el caso de Aragón, La Rioja, Cantabria y Navarra)
}

\author{
Antonio Fanlo Loras \\ Prof. Titular de Derecho Administrativo. \\ Universidad de Zaragoza
}

SUMARIO: INTRODUCCION. I. COMPETENCIAS EN MATERIA DE AGUAS DE LAS COMUNIDADES AUTONOMAS QUE PERTENECEN A CUENCAS INTERCOMUNITARIAS. 1) Potestad de demanializar las aguas y su titularidad. 2) La protección del dominio público hidráulico. 3) El régimen de aprovechamiento del dominio público hidráulico. 4) La problemática delimitación de las obras hidráulicas de interés regional. II. FORMAS INSTITUCIONALES DE COOPERACION. 1) Los convenios de colaboración. 2) La incorporación de las Comunidades Autónomas a los Organismos de Cuenca. III. LA ORGANIZACION ADMINISTRATIVA DE LAS COMUNIDADES AUTONOMAS EN RELACION CON LAS AGUAS. IV. AGUAS MINERALES Y TERMALES. V. REFORMA Y DESARROLlO AGRARIO. 1) Aragón. 2) Navarra. VI. MEDIO AMBIENTE. 1) Protección de la flora y de la fauna: caso de Navarra. 2) Espacios naturales. a) Aragón. b) La Rioja. 3) Protección de la calidad de las aguas. Vertidos de aguas residuales: legislación navarra. VII. SANIDAD. 1) Calidad de las aguas de baño. 2) Aguas potables de consumo público. VIII. ORDENACION DEL TERRITORIO Y URBANISMO. IX. MONTES.

\section{INTRODUCCION}

Aglutinar en una misma conferencia la exposición del Derecho de Aguas relativo a cuatro Comunidades Autónomas (Aragón, la Rioja, Cantabria y Navarra) con el pretencioso rótulo, además (autonomía y reintegración foral), con el que se acompaña su título, pudiera llevar a los participantes en estas II Jornadas sobre el Derecho de Aguas ${ }^{1}$, a sacar precipitadas

\footnotetext{
${ }^{1}$ El contenido de este trabajo constituye mi participación en las II Jomadas sobre Derecho de las Aguas, celebradas los días 12 y 13 de marzo de 1992, organizadas por el Seminario Permanente de las Aguas (fruto de la colaboración de la Universidad de Zaragoza con la Confederación Hidrográfica del Ebro), dedicado este año a la Legislación del Agua en las Comunidades Autónomas. Mi conferencia tuvo por título "Aragón, La Rioja, Cantabria y Navarra, autonomía y reintegración foral». Al publicarlo ahora he creído conveniente darle un título más genérico, puesto que responde mejor al contenido de la misma. En este sentido, vendría a ser una guía o vademecum de las posibilidades de
} 
conclusiones acerca del posible contenido de la misma, de la importancia relativa de la legislación de las Comunidades Autónomas que se agrupan a estos efectos expositivos, en definitiva, a interrogarse acerca del criterio que ha podido guiar al Director de las Jornadas para fijar esta agrupación y título específico que se aparta de la escueta referencia a la legislación de aguas común al resto de las Conferencias.

Resulta cierto que la legislación dictada por las Comunidades Autónomas cuya exposición me ha correspondido, no tiene la importancia cuantitativa ni cualitativa de otras que justifican una atención monográfica en estas Jornadas. Sin embargo, hay una razón que, creo se compartirá, justifica la opción adoptada. La razón integradora (su hilo conductor) no es otra que la pertenencia común de los territorios de dichas Comunidades Autónomas al ámbito geográfico de la Confederación Hidrográfica del Ebro 2, organismo de cuenca gestor de las competencias que en materia de aguas corresponden al Estado por ser esta una cuenca hidrográfica intercomunitaria. La cuenca del río Ebro no sólo recorre, en su búsqueda del mar, el territorio (espacio geográfico) de estas Comunidades Autónomas sino que cruza horizontalmente el sistema vertical de distribución de competencias (en materia de aguas), en definitiva, los espacios administrativos estancos en relación a otras materias pero permeables, y nunca más apropiada la expresión, al fluir del agua.

La exposición conjunta del Derecho de Aguas relativo a las Comunidades de Cantabria, La Rioja, Navarra y Aragón desde su condición de territorios pertenecientes e integrados en el ámbito de la Confederación Hidrográfica del Ebro, ofrece, desde mi punto de vista, particular interés para comprobar, extrapolándolo, el alcance real de las competencias que en materia de aguas corresponden a las Comunidades Autónomas integradas en una cuenca intercomunitaria. En efecto entre ellas, las hay que han accedido a la autonomía a través del procedimiento del art. 143

intervención de las Comunidades Autónomas cuyo territorio pertenece a cuencas intercomunitarias en materia de aguas, atendiendo a los títulos tanto específicos como sectoriales. Agradezco al Director de las Jornadas y alma del Seminario de las Aguas, el profesor Antonio Embid Irujo, la amabilidad que tuvo invitándome a participar y ahora al permitirme publicar por separado mi intervención. Dichas conferencias han sido publicadas en el vol. col. dirigido por EMBID IRUJO, Legislación del agua en las Comunidades Autónomas, Tecnos, Madrid, 1993.

2 La Confederación Hidrográfica del Ebro fue creada por el Real Decreto de 5 de marzo de 1926, el mismo día que se aprobó el Decreto regulador de las entonces llamadas Confederaciones Sindicales Hidrográficas (Gaceta de Madrid de 6 de marzo de 1926), y sirví de modelo a todas las constituidadas con posterioridad. Sobre ella véase el libro de quien fue el artífice del Decreto regulador y primer Director Técnico de la del Ebro, M. LORENZO PARDO La Confederación del Ebro, C.I.A.P., MADRID, 1930. Tras la vigente ley de Aguas de 2 de agosto de 1985, ha sido refundada por el R.D. 931/1989, de 21 de julio. 
CE (Cantabria, La Rioja, Aragón), circunstancia politico-constitucional que determina el techo competencial ${ }^{3}$ al que debieron ajustarse sus Estatutos de Autonomía (art. 148.1.10 $\mathrm{CE}$ ), al menos transitoriamente, como luego se verá 148.2 CE). Pero también las hay (caso de Navarra), con autonomía amplia y con techo competencial referido en este caso al art. 149.1.22 $\mathrm{CE}$, en virtud del procedimiento peculiar ${ }^{4}$ seguido por esta Comunidad para la actualización de su régimen foral al marco constitucional (D.A. $\left.1^{\text {a }} \mathrm{CE}\right)$.

Junto a esta circunstancia, otra de naturaleza geográfica (de incidencia no provisional sino permanente mientras no se altere el criterio geográfico para la distribución de competencias en materia de aguas) condiciona su ámbito competencial. La existencia de Comunidades cuyo territorio pertenece íntegramente a cuencas hidrográficas intercomunitarias (casos de La Rioja, Navarra ${ }^{5}$ y Aragón ${ }^{6}$ ), junto a otras

3 Es absolutamente necesario tener presentes los argumentos empleados por la STC 227/1988, de 29 de noviembre, relativa a la Ley de Aguas de 1985, en cuanto al sistema de distribución de competencias Estado-Comunidades Autónomas en materia de aguas, en particular los FF.JJ. 13 y ss. en los que se hace especial referencia a la interpretación de los preceptos del Estatuto de Cantabria en materia de aguas. Esta circunstancia ha concluido tras la Ley Orgánica 9/1992, de 23 de diciembre.

4 El libro de José Antonio RAZQUIN LIZARRAGA, Fundamentos jurídicos del amejoramiento del Fuero. Derechos Históricos y Régimen Foral de Navarra, Gobierno de Navarra, 1989, constituye el esfuerzo más notable y acertado de comprensión y acercamiento entre la visión foralista y la constitucionalista en relación a la posición de Navarra en el nuevo marco constitucional. Muy recientemente véase el libro colectivo dirigido por Sebastián MARTIN RETORTILLO, Derecho Público Foral de Navarra. El amejoramiento del Fuero, Gobierno de Navarra-Civitas, Madrid, 1992.

5 Sin olvidar que existen cuencas en el territorio navarro (cuenca del rio Luzame) que, tras penetrar en el territorio francés, vierten en el Atlántico, lo que suscita una peculiar posición de esas aguas, como consecuencia de los compromisos que pueda tener el Estado en cumplimiento de acuerdos y convenios internacionales, art. 15. b LAg. En todo caso, cabe perfectamente que Navarra, sin perjuicio de la responsabilidad última del Estado, ejecute en relación a las mismas las competencias de administración y gestión de dicha cuenca, como admite en principio la STC 227/1988, de 29 de noviembre, F.J. 21.b) y se admitió en relación con el río Garona, en el R.D. 2646/1985, de 27 de diciembre de traspaso de funciones y servicios a la Generalidad de Cataluña en materia de obras hidráulicas. Sobre la cuestión en general de las competencias de ejecución que corresponden a las Comunidades Autónomas en materia de relaciones internacionales, véase POMED SANCHEZ, L.A., «La proyección exterior de las Comunidades Autónomas ante el Tribunal Constitucional", RAP, 123(1990), pp. 211 y ss.

6 También en este caso no debe olvidarse que pese a su escasa importancia tienen la condición de aguas intracomunitarias, la cuenca endorreica de la laguna de Gallocanta de $551 \mathrm{Km}^{2}$. (aunque opiniones técnicas solventes afirman que esa cuenca endorreica no tiene salida "superficial", pero sí que la tiene subterránea a la cuenca del río Jiloca, circunstancia que de confirmarse llevaría a considerarlas como aguas intercomunitarias) y algunos ibones del Pirineo aragonés, así como también existen cuencas (la del río Adour, 
(caso de Cantabria), parte de cuyo territorio pertenece a cuencas intercomunitarias (un 10\% aproximadamente a la del Ebro) pero que también cuenta con cuencas intracomunitarias, aunque ahora integradas en la Confederación Hidrográfica del Norte. Oportunidad, pues, de contrastar las diferencias competenciales que existen en materia de aguas derivadas del sistema constitucional de distribución de competencias entre Estado y Comunidades Autónomas, a resultas de techos competenciales diferentes (circunstancia político-constitucional que, a lo que parece tras el reciente Pacto Autonómico ha de incidir por poco tiempo) y de su pertenencia a cuencas intercomunitarias (condicionante geográfico de consecuencias permanentes en tanto no se altere, lo que no parece vaya a suceder, el criterio de gestión unitaria a partir de la cuenca hidrográfica). Averiguar cómo inciden, en definitiva, estas circunstancias en la legislación dictada hasta la fecha y cuya exposición es objeto de la presente conferencia.

Con carácter previo, resulta imprescindible fijar correctamente el marco competencial en virtud del cual se dicta esta legislación regional, así como su alcance preciso, tal como resulta hoy de una correcta lectura del bloque de la constitucionalidad Constitución, Estatutos, Ley de Aguas, jurisprudencia constitucional), echando mano cuando la ocasión lo requiera de las reflexiones, ya abundantes de la doctrina ${ }^{7}$. Se

de $17 \mathrm{~km}^{2}$ ) que vierten al Atlántico, tras penetrar en territorio francés. Su inclusión en el ámbito territorial de la Confederación Hidrográfica del Ebro establecida por el R.D. 650/1987, de 8 de mayo (art. 1,8) está justificada por la falta (transitoria) de competencia de Aragón al tener como techo el art. $148.1 .10^{3} \mathrm{CE}$.

7 Sobre la problemática que plantea la distribución constitucional en materia de aguas, véase por todos, la contribución de MENENDEZ REXACH al libro escrito en colaboración con GALLEGO ANABITARTE y DIAZ LEMA, El Derecho de Aguas en España, MOPU, Madrid, 1986, en particular, pp. 543 y ss., y del mismo autor MENENDEZ REXACH, A., «Legislación de aguas, ordenación del territorio y medio ambiente", en Ley de Aguas: análisis de la jurisprudencia constitucional, INAP, Madrid, 1990, pp. 95 y ss.; Véase también ORTIZ DIAZ J., "Competencias establecidas en la Constitución y en los Estatutos de las Comunidades Autónomas respecto al sector hidráulico", RAP, 99, 1982. SANCHEZ BLANCO, "Recursos y aprovechamientos hidráulicos, REDA 34 (1982), pp. 425-439; Lorenzo MARTIN RETORTLLO, "Aguas subterráneas" y "aguas que discurren integramente dentro del territorio", RAP 113 (1987), pp. 401-424; F. DELGADO PIQUERAS, "La distribución de competencias Estado-Comunidades Autónomas en materia de aguas: la sentencia del Tribunal Constitucinal de 29 de noviembre de 1988", RAP, 118 (1989); J.L. MEILAN GIL y J.F. RODRIGUEZ-ARANA, "Las competencias del Estado y de las Comunidades Autónomas en materia de aguas: especial referencia a los casos gallego y canario", Autonomíes, 11 (1990); PEREZ PEREZ E., "Alcance de la competencia de las Comunidades Autónomas en materia de encauzamiento y defensas de márgenes», en La Ley, de 26 de mayo de 1989; DIEZ MORENO A., "Las aguas. Un motivo para delimitar la competencia entre el Estado y las Comunidades Autónomas", Revista Jurídica de Castilla-La Mancha, 8 y 9, 1989-1990; SANCHEZ BLANCO A., "Distribución constitucional de competencias en materia de recursos naturales (aguas, minas, montes)", en Estudios sobre la Constitución española. Homenaje al Profesor Eduardo Garcia de Enterria, Ed. Civitas, Madrid, 1991, tomo IV; muy recientemente Sebastian MARTIN RETORTILLO, "Competencias constitucionales y autonómicas en materia de aguas", RAP 128, 1992, pp. 23-83. 
trata de una labor interpretativa de síntesis tanto de los títulos específicos que en materia de recursos y aprovechamientos hidráulicos contienen los Estatutos de las cuatro Comunidades Autónomas como aquellos otros no específicos pero con incidencia indirecta en la materia (Epígrafe I). No se trata de reproducir aquí el debate en torno a nuestro complejo sistema constitucional de distribución de competencias en materia de aguas ${ }^{8}$, cuyo estado de la cuestión ha trazado el profesor Embid Irujo en la primera de las conferencias de estas Jornadas ${ }^{9}$. Sus conclusiones deben tenerse bien presentes ahora. Como recordaba dicho autor la STC 227/1988, de 29 de noviembre marca un hito en el debate doctrinal sobre la distribución de competencias en materia de aguas, un antes y un después, tras el cual parte del debate doctrinal anterior pierde todo su sentido.

Competencias, como se verá en su momento, prácticamente limitadas a las obras hidráulicas que sean de interés de la Comunidad Autónoma. Las muy limitadas funciones que en materia de aguas corresponden a las Comunidades Autónomas pertenecientes a cuencas intercomunitarias, nos empuja necesariamente a descubrir la importancia de las formulas institucionales de cooperación previstas en el actual ordenamiento. La fórmula de los convenios de cooperación prevista en el art. $23 \mathrm{LAg}$, como la participación de representantes de las CCAA en los organismos de cuenca (Junta de Gobierno y Consejo del Agua), deben de adquirir de cara al futuro toda la importancia que merecen en detrimento de forzadas interpretaciones del marco competencial que están llamadas al fracaso (Epígrafe II). Ello no constituye impedimento para que se exponga cómo se ha resuelto organizativamente en el interior de cada Comunidad Autónoma la gestión de las competencias que puedan corresponderles en materia hidráulica, adelantando que no puede hablarse con propiedad de la existencia de una Administración hidráulica regional en estos casos, con todas las salvedades que quieran hacerse y que en su momento veremos Epígrafe III).

Pero, como ha señalado la STC 227/1988, de 29 de noviembre, la distribución de competencias en materia de aguas, no se agota con el examen de los títulos específicos $\left(148.1 .10^{\mathrm{a}}\right.$ y $149.1 .22^{\mathrm{a}} \mathrm{CE}$ y los correspondientes

8 Recúerdese que la dificultad interpretativa arranca de las deficiencias técnicas que ofrece la redacción de los arts. $148.1 .10^{\mathrm{a}}$ y $149.1 .22^{\mathrm{a}} \mathrm{Ce}$. Sobre los intentos de su corrección en el mismo proceso constituyente, téngase en cuenta el testimonio particularmente valioso del entonces senador y Catedrático de Derecho Administrativo, Lorenzo MARTIN RETORTILLO, Materiales para unas Constitución, Akal, Madrid, 1984, pp. 344-355.

9 EMBID IRUJO «Las competencias sobre las aguas continentales. Planteamiento normativo y realidad jurídica». Esta como las restantes conferencias están publicadas en el vol. col. por él dirigido, Legislación del agua en las Comunidades Autónomas, Tecnos, Madrid, 1993. 
de los distintos Estatutos) sino que en esta materia se produce un entrecruzamiento competencial de distintos títulos (ordenación territorial y urbanismo, agricultura, medio ambiente, espacios naturales protegidos, sanidad, montes, régimen local), que deben tenerse en consideración para delimitar correctamente el cuadro competencial global. Esta nueva perspectiva nos describirá la virtualidad insospechada de algunos títulos aparentemente apartados de lo que constituye el núcleo duro del título específico relativo a recursos y aprovechamientos hidráulicos. Ellos nos permitirá reparar en la muy diversa legislación sectorial dictada por las Comunidades Autónomas consideradas, que evidencia el entrecruzamiento competencial señalado y la legitimidad de estas intervenciones regionales atendiendo a cada caso concreto (financiación agraria; protección medioambiental; espacios naturales protegidos, calidad de aguas) ( Epígrafes IV a IX).

\section{COMPETENCIAS EN MATERIA DE AGUAS DE LAS COMUNL. DADES AUTONOMAS QUE PERTENECEN A CUENCAS IN- TERCOMUNITARIAS}

Las previsiones estatutarias específicas están recogidas en los arts. 22.8 y 25.1.a y b,E. Cantabria, 8.1.4), E. Rioja, 35.1.11), E. Aragón y 44. 5 y 6, LORARF Navarra, que creo innecesario reproducir.

Dichos preceptos estatutarios deben interpretarse, de conformidad con STC $227 / 1888$, de 29 de noviembre (FJ. 13 y ss.) atendiendo a los techos competenciales establecidos en función de la vía de acceso a la autonomía. Para La Rioja, Cantabria y Aragón, su techo competencial viene establecido por el contenido del art. 148.1.10 ${ }^{\mathrm{a}} \mathrm{CE}$. Las competencias de estas tres Comunidades, cualesquiera que sean las expresiones con que se plasmen en sus Estatutos, no pueden exceder el ámbito material acotado por el art. 148.1.10 ${ }^{\mathrm{a}} \mathrm{CE}$, aunque no hayan invadido competencias reservadas al Estado, según el art. 149.1.22 $2^{\mathrm{a}} \mathrm{CE} \mathrm{10}$, tal como expresamente advierte la STC 227/1988, de 29 de noviembre, para el

\footnotetext{
10 Así Cantabria no ha podido asumir competencias en materia de aguas intracomunitarias ni en aguas subterráneas. Por mayores razones, es ineficaz la referencia contenida en el Estatuto de Aragón a la ordenación de recursos y aprovechamientos intracomunitarios (todas las aguas de Aragón son intercomunitarias, salvo la cuenca endorreica de Gallocanta) y a las aguas subterráneas. Sobre la extralimitación del Estatuto aragonés, con anterioridad a la STC $227 / 1988$, de 29 de noviembre, ya se había pronunciado J. PEMAN GAVIN en su comentario al art. 35.1.11 en la obra colectiva dirigida por J. BERMEJO VERA, Comentarios al Estatuto de Autonomía de la Comunidad Autónoma de Aragón, IE$A L$, Madrid, 1985, pp. 391-396. También antes de la sentencia constitucional y con toda rotundidad se manifestó en un detenido estudio de la cuestión Lorenzo MARTIN RETORTILLO en trabajo citado en nota anterior.
} 
caso de Cantabria 11 (F.J. 13). El techo competencial de Navarra es en teoría más alto (la reserva al Estado de la competencia del art. 149.1.22 $2^{\mathrm{a}} \mathrm{CE}$ ) pero en la práctica al no existir aguas intracomunitarias en Navarra, su plus competencial se extendería, únicamente, a las aguas subterráneas fósiles o no renovables (F.J. 16). Las consecuencias de la firma del Pacto Autonómico, analizadas por EMBID IRUJO en su conferencia, ponen de manifiesto que la circunstancia geográfica (tener o no aguas intracomunitarias) es la verdaderamente determinante de las competencias en materia de aguas.

Confirmada la constitucionalidad del criterio de cuenca hidrográfica (STC 227/1988, de 29 de noviembre, F.J. 15), el cuadro de competencias resultante en una cuenca intercomunitaria como la del Ebro, es el siguiente 12:

\section{1) La potestad de demanializar las aguas y su titularidad}

Al Estado corresponde la potestad de incorporar las aguas continentales, sean superficiales o subterráneas (en cuanto a categoría o género definido por sus características físicas o naturales homogéneas, que permiten hablar de un dominio público natural) al dominio público, considerado como dominio público estatal. El recurso (el agua y los demás bienes que integran el dominio público hidráulico) es de titularidad estatal 13, lo que no significa desconocer las competencias de gestión y aprovechamiento de las Comunidades Autónomas (F.J. 14), en los términos que se verá a continuación.

¿Quid con las aguas subterráneas fósiles o no fluyentes, no incorporadas por el art. 1.2. LAg al dominio público estatal? ¿Puede una

11 Limites que dejarán de existir en relación con sus cuencas intracomunitarias, si se aprueba el Pacto autonómico en los términos que se conocen.

12 Véase, tras la STC 227/1988, de 29 de noviembre, el trabajo de MENENDEZ REXACH, "Legislación de aguas, ordenación del territorio y medio ambiente", en La Ley de aguas: análisis de la jurisprudencia constitucional, vol. col. bajo la coordinación de A. SALVADOR, INAP, Madrid, 1990, pp. 97-117, algunas de cuyas ideas sigo en el presente trabajo.

13 De ahú la ineficacia de las previsiones del Estatuto de Aragón en cuanto al término "recursos", al que ya me he referido. Es significativo de esta ausencia de competencia en materia de aguas subterráneas el art. 2.1 del Decreto 167/1988, de 31 de octubre de la Diputación General de Aragón por el que se regulan determinados aspectos orgánicos y procedimientos en materia de aguas y de obras hidráulicas. En el se dice que "para la consecución de la indicada finalidad (coordinación administrativa), cualquier actuación relacionada, directa o indirectamente, con las competencias que actualmente tiene atribuidas la Comunidad Autónoma de Aragón o que deben atribuirsele, en materia de aguas, incluidas las subterráneas...» 
Comunidad como Navarra declararlas de dominio público regional? Algún autor lo ha defendido (Martín mateo ${ }^{14}$ ). Sin embargo, aplicando la doctrina de la STC 227/1988, de 29 de noviembre (F.J. 14 y 18), ratificada en la 149/1991, de 4 de julio (F.J. 1.C.) como bien perteneciente a la categoría del dominio público natural, su incorporación debe hacerse por ley estatal y la titularidad corresponde al Estado ${ }^{15}$. Cosa distinta es todo lo relativo a utilización y protección para lo que sí que existiría esa competencia regional, caso de que existan realmente esas aguas ${ }^{16}$.

¿Quid en relación con la titularidad de las aguas minerales y termales, competencia de las Comunidades Autónomas $\left(148.1 .10^{\mathrm{a}}\right.$ $\mathrm{CE}$ ), que debe ejercerse con arreglo a las «bases del régimen minero y energético" que establezca el Estado (art. 149.1.25 $\mathrm{CE}$ ), como algunos Estatutos precisan? Puede parecer extraño este interrogante, pues no debieran existir dificultades para entenderlas incluidas en el dominio público hidráulico 17 estatal en cuanto aguas continentales, aunque advirtiendo que aguas minerales y termales no son sinónimo de aguas subterráneas. Las dudas las suscita el art. 1.4 LAg que remite la regulación de aquellas a su legislación específica que no es otra que la Ley de Minas de 21 de julio de 1973. ¿La remisión lo es sólo en relación con su aprovechamiento o también con el dominio? La cuestión no es un mero pasatiempo intelectual. El art. 2.2 LMi diferencia estos dos aspectos. Señala, en efecto, que: «en cuanto al dominio de las aguas, se estará a lo dispuesto en el Código Civil y Leyes

\footnotetext{
14 MARTIN MATEO, El reto del Agua, Alicante, 1989, p. 221. Así mismo lo hizo en la conferencia impartida por el citado profesor en estas II Jornadas sobre el Derecho del Agua, con el título "La legislación en materia de aguas de la Comunidad Autónoma Valenciana", Legislación..., pp. 87-100.
}

15 J.L. MOREU BALLONGA, a la vista de la doctrina constitucional señala que "sólo una nueva ley estatal podría pasar también al dominio público las aguas subterráneas "no renovables" pese a quedar éstas bajo la competencia legislativa "exclusiva" de ciertas Comunidades Autónomas (las del art. $151 \mathrm{CE}$, que para sí la hayan recabado en los Estatutos)", Nuevo régimen jurídico de las aguas subterráneas, Universidad de Zaragoza, Zaragoza, 1990, p. 195.

16 En estas II Jormadas hubo pronunciamientos técnicos autorizados que negaron la existencia de aguas subterraneas fósiles peninsulares, por lo que la polémica jurídica quedaría vaciada de contenido. Otras opiniones técnicas defienden la existencia de esas aguas (por ejemplo en la zona de Monegros en Aragón), pero de naturaleza salobre, lo que explicaría la existencia de importantes yacimientos de sal en las proximidades del Ebro.

17 Para E. PEREZ PEREZ, no ofrece duda alguna su condición de demaniales, sin perjuicio de la remisión a la legislación específica en relación con la utilidad, pero no a su titularidad. Comentarios al Código Civil y Compilaciones Forales, T.V., vol. 3. . Artículos 407 a 427 del Código Civil y Ley de Aguas, $2^{\mathrm{a}}$ Ed., EDERSA, Madrid, 1991, p. 78-79. 
especiales, sin perjuicio de lo que establece la presente Ley en orden a su investigación y aprovechamiento" 18 . Sin embargo, la LAg. 1985 demanializa todas las aguas continentales superficiales y subterráneas renovables ${ }^{19}$. Por ello no acaba de entenderse 20 bien esa remisión a la LMi, salvo que lo sea a los efectos de su aprovechamiento, entendiendo que en cuanto al dominio, forman parte del dominio público hidráulico estatal o que, caso de no entenderlas ya incluidas, solo una ley estatal puede hacerlo, como hemos dicho en relación con las aguas subterráneas fósiles.

Que la cuestión no parece estar del todo clara lo confirma la Ley $8 / 1990$, de 28 de diciembre, de aguas minerales y termales de CastillaLa Mancha que, en su art. 1, se ve en la necesidad de precisar que «las aguas minerales y termales constituyen un recurso declarado de utilidad pública, que forma parte del dominio público del Estado en los términos que establecen las legislaciones básicas estatales de aguas y minas» 21. La ley cántabra $2 / 1988$, de 26 de octubre de Fomento, ordenación y aprovechamiento de los Balnearios y de las agua mineromedicinales y/o termales, no se plantea problema alguno respecto a la titularidad.

\footnotetext{
18 Este párrafo, a continuación de otro en el que se declaran de dominio público todos los yacimientos de origen natural y demás recursos geológicos, tenía pleno sentido en 1973, puesto que, en ese momento, tanto en el Código Civil como la LAg 1879, rige el principio de accesión en cuanto al dominio de los manantiales o de las aguas subterrá. neas alumbradas natural o artificialmente (art. $408.11^{\circ}$ y $3 .^{\circ}$ en relación con el art. 418 $\mathrm{CCi}$ ), correspondiendo la propiedad al dueño del terreno en el que nacen o al que las alumbró (dueño o investigador).
}

19 Por lo general las aguas minerales y termales son aguas subterráneas alumbradas natural $o$ artificialmente, aunque pueden existir aguas que tengan las características de las minerales que sean superficiales.

20 A.GUAITA se refiere al "doble y ambiguo tratamiento legal" de las aguas minerales que la Ley de Minas renuncia a ocuparse del dominio o propiedad, Derecho Administrativo. Aguas, Montes, Minas, $2^{\mathrm{a}}$ Ed. Cívitas, Madrid, p. 347, De ahí, también, la perplejidad que le suscita esta remisión a PARADA VAZQUEZ, Derecho Administrativo. III Bienes Públicos y Urbanismo, $4^{a}$ Ed. M. Pons. Madrid, pp. 256-258. Para este autor, las aguas minerales pueden ser (en cuanto a la titularidad) de dominio público o privado con arreglo a los criterios del Código Civil, p. 257. En cuanto a la regulación de su aprovechamiento debe estarse a la legislación de minas. Llama la atención que este autor no tenga en cuenta la competencia asumida por las Comunidades Autónomas en esta materia. Ninguno de los dos autores se plantea si las Comunidades Autónomas pueden declararlas de dominio público regional.

21 Parece evidente que la ley castellano-manchega, exista ya esa declaración demanial de las aguas minerales y termales o venga a establecerla, se extralimita, pues la demanialización de bienes del dominio natural corresponde, en todo caso, a la ley estatal. 


\section{2) La protección del dominio público hidráulico}

Al Estado, y por él a los Organismo de Cuenca, corresponde la protección del dominio público hidráulico, como aspecto esencial del régimen de dominio público (STC 227/1988, de 29 de noviembre, F.J.18), ello no sólo en las cuencas intercomunitarias, en orden a asegurar la integridad de los bienes del dominio público hidráulico, competencia estatal derivada tanto de la titularidad que ostenta como sobre todo por la titularidad de la competencia sobre medio ambiente (legislación básica incluido el desarrollo legislativo reglamentario) ${ }^{22}$. Ello no es obstáculo para que, por la conexión de este aspecto con otros títulos competenciales (particularmente los medioambientales), las Comunidades Autónomas que pertenecen a cuencas intercomunitarias tengan competencias concretas, como en su momento se verá, cuyos contenidos debe recoger la planificación hidrológica de la cuenca (art. 41.2. LAG), llegando en ocasiones hasta condicionar el aprovechamiento y utilización del dominio público hidráulico (medidas de protección dictadas por las Comunidades Autónomas, por ejemplo en relación a una zona húmeda declarada Reserva Natural).

Más amplias pueden ser, y de hecho son, las competencias de las Comunidades Autónomas en materia de protección del dominio público hidraúlico en relación con las cuencas intracomunitarias. Les corresponde la ejecución de las medidas previstas en la legislación estatal (autorizaciones sobre vertidos), y de las normas de desarrollo o adicionales que puedan dictar (canon de saneamiento u otros específicos) ${ }^{23}$.

\section{3) El régimen de aprovechamiento del dominio público hidráulico}

Corresponde al Estado, y por él a los Organismos de Cuenca, establecer el régimen jurídico de utilización (los aprovechamientos en la terminología tradicional) y policía de aguas (buen orden en el uso y aprovechamiento) del dominio público hidráulico en las cuencas intercomunitarias

\footnotetext{
22 Así se deduce de las SSTC 227/1988, de 29 de noviembre y 149/1991, de 4 de julio, relativa a la Ley de Cortes, en especial FJ. 1, D, dentro de las consideraciones generales.

23 De la amplitud de estas medidas ejecutivas da idea la reciente ley catalana 19/1991, de 7 de noviembre, de Reforma de la Junta de saneamiento. Las funciones que ahora se le atribuyen en el art. 5, superan con creces las previstas en la legislación que se deroga y que estaban en la línea de las traspasadas por el Estado en el Decreto de obras hidráulicas (la autorización de vertidos correspondía al Estado si bien la tramitación a la Generalidad estableciéndose un ingenioso sistema de silencio administrativo, caso de que la Administración del Estado no resolviera en el plazo de 6 meses). Ahora la autorización corresponde a la Junta de Saneamiento (art. 5.1.K).
} 
como la del Ebro. La gestión unitaria del agua («recurso») en el ámbito integral de la cuenca impide, de manera absoluta, que las Comunidades Autónomas, tanto las de autonomía limitada (La Rioja, Cantabria y Aragón) como las de autonomía amplia (Navarra) puedan ejercer ningún tipo de competencias en materia de aprovechamiento (esto es, que puedan disponer por sí mismas del agua o de los otros bienes del demanio hidráulico).

Como exigencia ineludible de la gestión unitaria en el ámbito de la cuenca, definida en el art. $14 \mathrm{LAg}$ y ratificada por la STC 227/1988, debe rechazarse la interpretación propuesta, en su día, por Menendez Rexach del concepto de "aprovechamiento" en cuanto a las competencias que pueden asumir las Comunidades Autónomas en relación con los aprovechamientos hidráulicos en cuencas intercomunitarias. Según este autor las Comunidades Autónomas serían competentes en relación con aquellos caudales cuyo "aprovechamiento discurra íntegramente por el territorio de aquellas, lo que sucederá cuando los canales, acequias, conducciones y demás obras construidas para el encauzamiento artificial de las aguas objeto del aprovechamiento se localicen en su totalidad en el territorio de una Comunidad" ${ }^{24}$, interpretación que además de ser contraria al principio de gestión unitaria e integrada del agua ha merecido un abierto rechazo en la STS de 17 de julio de 1990 (arz. 6635), caso de los Canales de Urgel 25. Las Comunidades Autónomas carecen de competencias en

\begin{abstract}
24 MENENDEZ REXACH, El Derecho..., pp. 561 y ss. A esta tesis se han sumado ARIÑO ORTIZ y RODRIGUEZ ARANA, ob. cit. Para MENENDEZ REXACH confirmaría su interpretación el que se distinga en el art. 21, párrafos b) y c) LAg entre «administración y control del dominio público hidráulico» y "administración y control de los aprovechamientos" reservándose a los Organismos de Cuenca exclusivamente "la administración y control de los aprovechamientos de interés general o que afecten a más de una Comunidad Autónoma", redacción que, en mi opinión, puede traer origen de la incorrecta utilización del término "aprovechamientos" que se hace en la misma Constitución. Si se entiende por aprovechamiento las obras hidráulicas el criterio del art. 21.c LAg (interés general o que afecte a más de una Comunidad), es correcto; si se entiende que hace referencia al "agua» no cabe otra competencia que la del Organismo de Cuenca en la intercomunitarias.
\end{abstract}

25 En la sentencia, la Comunidad General de Regantes de los Canales de Urgel recurre dos resoluciones de la Dirección General de Obras Hidráulicas de la Generalidad de Cataluña por las que se le ordenaba el suministro a una población de un caudal mínimo de agua por día, por entender que carecía de competencia sobre dicho aprovechamiento. El TS, revocando la sentencia apelada señala que, la Generalidad carece de competencia sobre dichas aguas, pues, «no son los canales ni su ámbito de aprovechamiento los que determinan la competencia, sino el marco geográfico por el que discurren las aguas... resulta imposible atribuir competencia a la Generalidad catalana sobre los indicados Canales por el hecho de que están radicados en su totalidad en territorio catalán, ya que las aguas que por ellos discurren no tiene su principio y su fin en territorio de Cataluña». La distribución de los caudales concedidos corresponde a la Comunidad General, que según el art. 199.2 RDPH tiene las "funciones de policía, distribución y administración de las aguas que tengan concedida por la Administración" sin perjuicio de los recursos que proceden frente a sus actuaciones ante el Organismo de Cuenca. 
materia de aprovechamientos (disposición del agua, del «recurso») en las cuencas intercomunitarias 26 , al margen ahora de la posible existencia de reservas de agua a favor de una Comunidad Autónoma, consecuencia de obras hidráulicas específicas (por ejemplo, una presa para un plan de riegos), cuya realización sea de la competencia regional, supuesto que parece admitir el art. 77 RAPA, sobre el que reflexionaré más adelante.

Por supuesto, lo dicho, es válido, en tanto referido a las cuencas intercomunitarias. Si el Pacto Autonómico llega a buen puerto, es indudable que Cantabria tendrá competencia para legislar sobre el régimen de utilización de los aprovechamientos en cuencas intracomunitarias, con respecto de la legislación básica dictada por el Estado, y para asumir las competencias ejecutivas de gestión del dominio público hidráulico, en los términos señalados por la STC 227/1988, de 29 de noviembre, F.J. 18.

\section{4) La problemática delimitación de las obras hidráulicas de inte- rés regional}

La única competencia que tienen las Comunidades Autónomas en las cuencas intercomunitarias, y ya veremos que resulta sumamente problemático precisar su contenido, es la referida a obras hidráulicas de interés regional, a la que hace referencia el art. $148.1 .10^{\mathrm{a}} \mathrm{CE}$ («los proyectos, construcción y explotación de los aprovechamientos hidráulicos, canales y regadíos de interés de la Comunidad Autónoma"). Hoy la única manera de dar una cabal interpretación del significado que aquí tiene el concepto "aprovechamientos hidráulicos» no es otra que entenderlo como "obras hidráulicas" por la referencia explícita a "los proyectos, construcción y explotación", diferente, por tanto, del significado que ha

\footnotetext{
26 No debe confundirse el contenido competencial derivado del título «legislación, ordenación u concesión de recursos y aprovechamientos hidráulicos", en cuencas inter o intracomunitarias, ex art. 149.1.22 ${ }^{\mathrm{a}}$, que hace referencia al agua, al bien («recurso») y a su utilización ("aprovechamiento»), con el relativo a «los provechos, construcción y explotación de los aprovechamientos hidráulicos", ex art. 148.1.10 $0^{2} \mathrm{CE}$, que hace referencia, exclusivamente, a las obras hidráulicas de interés regional, por más que se haya utilizado, tan impropiamente, el mismo concepto "aprovechamiento». De ahí el acierto de la enmienda del senador y catedrático de Derecho Administrativo Lorenzo MARTIN RETORTILLO, en el sentido de atribuir a las Comunidades Autónomas competencia en relación con las obras hidráulicas y no sobre aprovechamientos, puesto que éstos, no se «construyen", enmienda admitida en el texto aprobado por el Senado (aunque al final se incluye el término "aprovechamiento") y modificado, mezclando la redacción del 148.1.10 y 149.1.22 ${ }^{\mathrm{a}} \mathrm{CE}$ en la Comisión Mixta. Véase su libro Materiales..., pp. 344 y ss. Sobre el iter

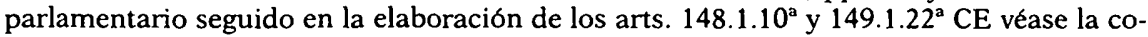
laboración de MENENDEZ REXACH, en El Derecho de las Aguas..., pp. 543 y ss.
} 
de darse a esa misma expresión cuando viene determinada por las funciones de «legislación, ordenación y concesión», título que permite a las Comunidades de Autonomía amplia asumir competencias sobre el régimen de utilización de los aprovechamientos en sus cuencas intracomunitarias 27.

Puede parecer que la interpretación aquí propuesta constituye un reduccionismo inaceptable del contenido competencias previsto en el art. 148.1.10 $\mathrm{CE}$. ¿Cómo explicar, entonces, las competencias que corresponden a la Comunidad Autónoma de Madrid (de autonomía limitada y cuyo territorio pertenece a una cuenca intercomunitaria) en relación con el Canal de Isabel II 28, antes organismo autónomo estatal transferido a dicha Comunidad con todas las importantes funciones que ejerce en relación al abastecimiento y saneamiento de aguas de los municipios de dicha Comunidad, cuando dichas aguas son intercomunitarias? Sin restar importancia a la fuerza que pueda tener este argumento frente a la tesis defendida, creo que no es un argumento definitivo dado que es posible entender cuanto representa el Canal de Isabel II como una concesión de aguas cierto que muy peculiar (concesión no cuantificada sino "abierta» que constituye una verdadera reserva 29 de caudales de los ríos que nacen en el norte de la provincia en la falda sur de la sierra de Guadarrama), para solucionar un problema grave, pero concreto, primero el abastecimiento del municipio de Madrid y luego extendida para la totalidad de los municipios de la actual Comunidad Autónoma, concesión que conllevaría, como cualquier otra otorgada a una Comunidad de Usuarios, la "policía de aguas» correspondiente, como señala el art. 199.2 RAPA.

27 Que este sea el significado del concepto "aprovechamiento hidráulico» en el art. 148.1.1 $0^{\mathrm{a}} \mathrm{CE}$, no es contradictorio, como se ha señalado en una nota anterior, con el distinto que tiene ese mismo concepto en el art. 149.1.22 $\mathrm{CE}$. y que ha ratificado la STC 227/1988, de 29 de noviembre, F.J. 18 Pero es distinto no porque se predique de techos competenciales diferentes, porque afectan a Comunidades Autónomas según la vía de acceso a la autonomía, sino por el diferente contexto que los califica; «proyectos, construcción y explotación" en el art. $148.1 .10^{2} \mathrm{CE}$ y «legislación, ordenación y concesión", en el art. 149.1.22 ${ }^{\mathrm{a}} \mathrm{CE}$, lo que determina contenidos bien diferentes, pese a que se emplee el mismo concepto de «aprovechamientos».

28 Para el análisis de esta institución en el pasado véase M. BASSOLS COMA, "Abastecimiento de aguas y planeamiento metropolitano: el Estatuto orgánico del Canal de Isabel II, RAP, 76 (1975), pp. 357-399. Más recientemente, puede verse MORELL OCAÑA, "Abastecimiento y saneamiento de agua de la Comunidad de Madrid",en Estudios sobre el Derecho de la Comunidad de Madrid, vo. col. dirigido por R. Gómez Morant, Cívitas, Madrid, 1987, pp. 495-514.

29 Ya BASSOLS COMA apunta esta idea de la reserva de caudales ("generalización de la técnica de las reservas de los aprovechamientos a favor del Canal»), ob. cit., pp. 382 y ss. 
En la línea de la tesis aquí defendida, el contenido de la competencia sobre obras hidráulicas en cuencas intercomunitarias, asumida ex art. 148.1.10 $\mathrm{CE}$, es para todas las Comunidades Autónomas, sean de autonomía amplia o limitada transitoriamente, el mismo (obras hidráulicas de interés regional), puesto que no debe interferir en la interpretación de este título competencial, el significado derivado del art. 149.1.22 ${ }^{\mathrm{a}}$ $\mathrm{CE}$ que no juega en relación con estas cuencas, como se ha señalado en el apartado 3). Constituye ésta una primera conclusión cuya importancia puede apreciarse si se analizan los distintos Decretos de traspasos. Como luego se dirá, no parece que éstos hayan agotado, salvo el caso de Navarra, su techo competencial.

Los Decretos de transferencia de servicios del Estado a las Comunidades Autónomas en materia de obras hidráulicas constituyen un instrumento para ratificar la interpretación que atribuimos al concepto de "aprovechamiento". Al margen de la diferente terminología (obras hidráulicas en el caso de La Rioja 30 o de Navarra ${ }^{31}$; abastecimientos de agua, saneamientos y encauzamiento y defensa de márgenes de ríos en los casos de Cantabria 32 y Aragón ${ }^{33}$ ) dichos Decretos traspasan funciones y servicios en relación con obras hidráulicas ${ }^{34}$. En este sentido es, sumamente revelador el Decreto de traspasos a Navarra, que llega al techo máximo permititido del traspaso en materia de obras hidráulicas: "programación, aprobación, ejecución y explotación de aprovechamientos hidráulicos y demás obras hidráulicas, que se realicen en el territorio de Navarra, que no sean

30 R.D. $3022 / 1983$, de 5 de octubre, sobre transferencia de funciones y servicios del Estado a la Comunidad de La Rioja en materia de obras hidraulicas.

31 R.D. 139/1988, de 18 de noviembre, de traspaso de servicios de la Administración del Estado a la Comunidad Foral de Navarra en materia de obras hidráulicas.

32 R.D. 1661/1984, de 1 de agosto, de traspaso de funciones y servicios del Estado en materia de abastecimientos de agua, saneamientos y encauzamiento y defensa de márgenes de ríos.

33 R.D. 1598/1984, de 1 de agosto, de traspaso de funciones y servicios del Estado en materia de abastecimientos de agua, saneamientos y encauzamiento y defensa de márgenes de ríos.

34 Por supuesto que los Decretos no pueden añadir nada, desde el punto de vista competencial, que no se tenga en virtud de los respectivos Estatutos, como ha reiterado la jurisprudencia constitucional (STC 25/1983, de 7 de abril, 87/ y 88/1983, de 27 de octubre, $135 / 1984$, de 20 de diciembre, entre otras). Pese a ello no puede olvidarse, así lo ha reconocido también el Tribunal Constitucional su "valor interpretativo» (STC 48/1985, de 28 de marzo y 80/1985, de 4 de julio). 
de interés general del Estado y cuya realización no afecten a otra Comunidad" (apartado 2.a) 35 .

Sin embargo, es evidente que los traspasos efectuados a La Rioja, Cantabria y Aragón no agotan el contenido de la competencia sumida ex art. 148.1.10 $\mathrm{CE}$. Ni siquiera se traspasan en bloque las funciones y servicios correspondientes a abastecimiento de agua y saneamiento, encauzamiento y defensa de márgenes así como la de encauzamiento y defensa de márgenes en las «áreas urbanas" ${ }^{36}$, (además de regadíos 37 en el caso de la Rioja), sino, tan sólo, las «funciones inversoras» 38 (por cierto, bien menguadas y hasta casi ridículas ${ }^{39}$ ), en relación con los

\footnotetext{
35 Es significativo que en cuanto a las funciones atribuidas al Estado, además de la legislativa sobre aguas, se reserva la «ordenación y concesión de recursos hidráulicos, así como las autorizaciones para vertidos en cauces públicos y para el uso o aprovechamiento del dominio público hidráulico y la Policía de Cauces y Aguas, en las cuencas hidrográficas a las que pertenece Navarra", así como "programar, aprobar, ejecutar y explotar obras hidráulicas de interés general del Estado o cuya realización afecte a alguna otra Comunidad Autónoma». Se distingue muy correctamente entre "recursos», "aprovechamientos" y "obras hidráulicas". Con una terminología ahora totalmente correcta se reproduce el esquema seguido en el Decreto de traspasos en materia de obras hidráulicas a Cataluña, 2646/1985, de 27 de diciembre.
}

36 Ello quiere decir, que para las zonas no urbanas el Estado sigue disponiendo de los créditos, en definitiva de la financiación, necesarios para acometer las obras hidráulicas necesarias, extremo de dudosa constitucionalidad a la luz de la reciente STC 13/1992, de 6 de febrero (BOE de 3 de marzo de 1992), por el que se declaran inconstitucionales diversos preceptos y partidas presupuestarias de las leyes 33/1987, de 23 de diciembre y $37 / 1988$, de 28 de diciembre, de Presupuestos Generales del Estado para 1988 y 1989 (F.J. 4 a 7 ).

${ }^{37}$ La transferencia en materia de regadíos se hace para Aragón en el R.D. 643/1985, de 2 de abril, sobre valoración definitiva y ampliación de funciones traspasadas de la Administración del Estado a la Comunidad Autónoma de Aragón en materia de reforma y desarrollo agrario, con referencia a las actuaciones de reforma y desarrollo agrario de interés para Aragón, y la concurrencia en relación con las grandes superficies de transformación ya declaradas por el Gobierno de interés nacional.

38 Así, debe entenderse la referencia a la función de "programar, aprobar y tramitar, hasta el abono de las certificaciones, las inversiones en las obras...", lo que excluye la titularidad y explotación de dichas obras, que serán, por lo general, de titularidad municipal. Véase en relación con la valoración de Derechos de traspasos en materia de obras hidráulicas, MENENDEZ REXACH, El Derecho..., pp. 568-570 y 588-589.

39 Los recursos financieros destinados a sufragar los gastos originados por los servicios que se transpasan se cuantifican de la siguiente manera $22+19$ millones para Aragón; 4'5 para La Rioja; $9+2$ para Navarra; 4 millones para Cantabria. A la vista de esas cantidades, uno no acierta a entender muy bien el sistema de cálculo seguido para otras Comunidades Autónomas. Me refiero al dato, facilitado por el profesor J.M CASTELLS ARTECHE, en su conferencia sobre "La legislación en materia de aguas en el País Vasco". Según los datos publicados por la prensa del País Vasco, se estimaba en 3.500 millones la valoración de las transferencias en materia de obras hidráulicas, todavía no traspasadas al País Vasco, Legislación..., p. 148. 
mismos. Tal vez su justificación radique, como sugiere Menendez $\mathrm{Re}$ xach 40 en la calificación tradicional de esas obras como obras propias de las Corporaciones locales 41 , extremo del que queda constancia al referirse los Decretos de traspasos a la cooperación estatal a la financiación de tales obras («en relación con la función estatal de ayuda a las Corporaciones Locales»):

Es significativo, por lo demás, que los Decretos de traspasos, adelantándose a las previsiones de la Ley de Aguas de 1985, prevean la participación de una representación 42 de la Comunidad en las Confederaciones Hidrográficas a las que pertenece su territorio, así como la posibilidad de establecer fórmulas de colaboración 43 entre dichos organismos.

En definitiva, los Decretos de traspasos aportan un criterio interpretativo valioso en el sentido de entender que la competencia que corresponde a las Comunidades Autónomas ex art. 148.1.10 $\mathrm{CE}$ hace referencia exclusivamente a las obras hidráulicas (no, por tanto, en las cuencas intercomunitarias, a la disponibilidad de los recursos para su aprovechamiento), que a la postre, no es sino una especificación de la competencia que sobre obras públicas de interés regional recoge el art. 148.1.4 $\mathrm{CE}$.

40 MENENDEZ REXACH, El Derecho de las aguas..., pp. 569 y 588.

41 El art. 11 de la Ley General de Obras Públicas de 1987 incluye las de abastecimiento de agua a poblaciones entre las obras de competencia municipal.

42 Muy interesante es la temprana justificación que se da en el caso de La Rioja de la necesaria cooperación entre Estado y Comunidad en materia hidráulica. En el apartado D) relativo a las "funciones en que han de concurrir la Administración del Estado y la de la Comunidad Autónoma y formas de cooperación" se señala que "Las especiales características del ciclo hidrológico obligan al mantenimiento de la unidad de gestión dentro del marco de la cuenca hidrográfica. Para la salvaguarda de este principio universalmente aceptado y para el desarrollo coordinado de las funciones y competencias en que han de concurrir la Administración del Estado y las Comunidades Autónomas, se ejercerán dichas funciones y competencias a través de Organismos hidráulicos de cuenca en que, tanto la una como las otras, se encuentran representadas, junto con los usuarios». De una "representación proporcionada" se habla en el Decreto de traspasos para Aragón (Apartado B,b). En el de Cantabria se prevé la constitución de una Comisión específica en el seno de la Confederación Hidrográfica del Norte en la que participarán cuatro representantes de Cantabria (apartado D). Lógicamente, en el de Navarra, posterior a la LAg 1985, se indica que participará en los Organismos de cuenca de acuerdo con la legislación vigente (art. $23 \mathrm{LAg}$. desarrollado por el RAPA).

43 Muy importante resulta la fórmula de colaboración prevista en el apartado 4.c) del Decreto de traspaso de Navarra, puesto que el resultado de los acuerdos de cooperación establecidos entre la Administración del Estado y Navarra «se considerarán en los planes hidrológicos de las cuencas del Ebro y del Norte», extremo sobre el que, dado su interés, volveré más adelante. 
El problema, como ha quedado apuntado antes, es precisar qué debe entenderse por obras hidráulicas de interés regional 44 , extremo sobre el que no existe pronunciamiento directo en la STC 227/1988, de 29 de noviembre. Señalaré que, en mi opinión, constituye éste un tema no resuelto y que puede quedar permanentemente en la indefinición en cuanto su contenido es correlativo del contenido que el Estado discrecionalmente dé a las "obras de interés general» o que afecten a más de una Comunidad Autónoma. En todo caso, ni la Ley de Aguas ni los desarrollos reglamentarios de la misma (RDPH y RAPA) recogen criterios claros que permitan sentar pautas definitivas en esta cuestión. Por esta razón, considero que las fórmulas de cooperación pluridireccionales (Administración del Estado-Comunidades Autónomas, entre Comunidades Autónomas, entre aquellas en el seno de los Organismos de Cuenca junto con las Comunidades de Usuarios y las Corporaciones Locales) aparecen, siempre que se respeten determinadas reglas de juego por parte del Estado (trato igual a todas las Comunidades Autónomas a través de la territorialización del gasto público estatal), como un instrumento que facilitará la delimitación de responsabilidades, y la solución de eventuales conflictos puesto que no debe olvidarse que en materia de obras hidráulicas, el meollo radica en el tema de la financiación y a quién corresponda ésta.

La LAg no facilita la tarea de precisar qué deba entenderse por obras hidráulicas de interés regional. O más correctamente, no da los criterios para saber cuándo una obra es de interés general ${ }^{45} \mathrm{o}$ afecta a más de una Comunidad Autónoma ${ }^{46-47}$. El art. 44 LAg señala sin más precisiones que:

\footnotetext{
44 Sobre la cuestión véase los valiosos esfuerzos interpretativos hechos por MENENDEZ REXACH en El Derecho..., pp. 567-570 y 588-590, por más que concluya su discurso señalado que "el tema requiere una urgente clarificación", p. 590. Con posteridad a la STC 227/1988, de 29 de noviembre, véase el trabajo ya citado de DELGADO PIQUERAS, en especial, pp. 278/280.
}

45 Sobre la problemática jurídica de las obras públicas en general, es imprescindible la consulta de T.R. FERNANDEZ RODRIGUEZ, «Las obras públicas», RAP, 100-102 (1983), vol. III, pp. 2427-2469. Sobre el criterio «interés general" como delimitador de competencias entre el Estado y Comunidades Autónomas, véase el trabajo de J.BERMEJO VERA, "El "interés general" como parámetro de la jurisprudencia constitucional, en De la jurisprudencia del Tribunal Constitucional, Seminario de Profesores de la Facultad de Derecho, dirigido por Lorenzo Martín Retortillo, Zaragoza, 1985, pp. 391-428.

46 Corresponde al Estado (y por él al Gobierno de la Nación) definir el «interés general», STC 68/1984, de 4 de junio, F.J. 3 y 4.

47 Téngase en cuenta que en otros ámbitos competenciales en los que también se toma como criterio de delimitación competencial el interés "general" o "regional», la solución ha sido más fácil (caso de la Ley de carreteras, 25/1988, de 29 de julio en la que figura como 
«las obras públicas de carácter hidráulico que sean de interés general o cuya realización afecte a más de una Comunidad Autónoma habrán de ser aprobadas por Ley e incorporadas al Plan Hidrológico Nacional.

Obras cuya programación, aprobación y ejecución debe corresponder al Ministerio de Obras Públicas y Transportes (sin perjuicio de que su ejecución pueda encomendarse a los Organismos de Cuenca), de conformidad con el art. $21 \mathrm{~d}$. LAg 48 y con diferentes preceptos del R.D. 1316/1991, de 2 de agosto, de reestructuración de la Secretaría de Estado para las Políticas del Agua y el Medio Ambiente, relativas a infraestructuras necesarias para la gestión de los recursos hídricos de competencia de las Direcciones Generales de Obras Hidráulicas y de Calidad de las Aguas (arts. 1.dos,4; 3.uno, 2 y 3; 3 . cinco, 1 y $2 ; 4$. uno, $7 ; 4$. tres, 1. cuatro, 2 y 3 ).

Por su parte el art. 40.j) LAg señala como contenido obligatorio de los Planes Hidrológicos de Cuenca «las infraestructuras básicas requeridas por el Plan». ¿Guarda alguna relación este concepto con el de "obras de interés general»? ¿Son equivalentes? ¿Son de contenido distinto? Para mí no lo son. Pero, la posibilidad de que a través del establecimiento de esas infraestructuras hidráulicas básicas puedan desconocerse las competencias regionales ha sido resuelta por la STC 227/1988, de 29 de noviembre de la siguiente manera:

"La Administración del Estado puede prevenir en los planes hidrológicos las que sean indispensables o accesorias al ejercicio de las competencias de protección y aprovechamiento de los recursos hidráulicos, que le corresponden ordenar en las cuencas hidrográficas de su competencia, ya que en tales términos la previsión de infraestructuras resulta inherente al ejercicio de dichas competencias sobre el demanio hidráulico en tales cuencas, sin menoscabo de la colaboración y coordinación con las

Anexo la relación y denominación de las carreteras estatales) o en la Ley de Costas, $22 / 1988$, de 28 de julio, se recogen criterios más precisos para calificar una obra como de «interés general», en cuyo caso será competencia de la Administración del Estado (art. 111): a) las que sean necesarias para la protección, defensa y conservación del dominio público marítimo-terrestre, así como su uso; b) las de creación, regeneración y recuperación de playas; c) las de acceso público al mar no previstas en el planeamiento urbanístico; d) las emplazadas en el mar y aguas interiores, sin perjuicio de las competencias de las Comunidades Autónomas sobre acuicultura, en su caso y e) las de iluminación de costas y señales marítimas".

48 Según dicho precepto corresponden a los Organismos de cuenca «el proyecto, la construcción y explotación de las obras realizadas con cargo a los fondos propios del Organismo, y las que les sean encomendadas por el Estado", que no pueden ser otras que las de interés general, que deben aprobarse por ley y recoger el Plan Hidrológico Nacional. 
Comunidades Autónomas para disponer y ordenar otras infraestructuras no básicas, en el sentido expuesto a través de las correspondientes medidas de planificación territorial o de actuaciones específicas» (F.J. 20,E).

Importancia de esta precisión del Tribunal Constitucional, cuya operatividad queda centrada en la delimitación de qué sean "infraestructuras indispensables o accesorias», y su opuesta de "infraestructuras no básicas», ámbito en el que las Comunidades Autónomas pueden realizar «actuaciones específicas», según el Tribunal. Estamos, sin duda, ante conceptos que requieren una más concreción. Eso es lo que persigue el art. 85 RAPA, al definir el concepto de infraestructura básica. Según este precepto,

"A los efectos de su obligatoria inclusión en el Plan Hidrológico de cuenca, se entenderá por infraestructuras básicas las obras y actuaciones que, influyendo significativamente en el ámbito hidráulico en que se insertan, forman parte integrante de los sistemas de explotación que hacen posible la oferta de recursos prevista por el Plan para los diferentes horizontes temporales».

Parece evidente que el intento de cerrar el círculo interpretativo no lo ha culminado el Reglamento. Que todavía hay un margen interpretativo (¿cuándo un obra influye significativamente en la oferta de recursos?). Pero, en todo caso, adviértase de la necesaria inclusión de estas infraestructuras básicas en el Plan Hidrológico de Cuenca a cuyos efectos se recogerá un Catálogo de las mismas (art. 85.3 RAPA). En aplicación de la interpretación del Tribunal Constitucional, habría que entender que aquellas infraestructuras básicas que influyen significativamente en la oferta de recursos deben ser de competencia del Estado (¿y por tanto de interés general?), por lo que el Catálogo de estas infraestructuras que debe recoger el Plan Hidrológico de cuenca podría considerarse el instrumento de concreción de las obras competencia del Estado. ¿De qué forma? De entre las infraestructuras básicas recogidas por el Plan, unas que se propone sean declaradas por el Gobierno de la Nación de interés general y recogidas en el Plan Hidrológico Nacional. El resto de las obras hidráulicas pueden ser competencia de las Comunidades Autónomas, del Organismo de Cuenca, de las Corporaciones Locales o de las Comunidades de Usuarios. Por tanto, en relación a estas últimas, no hay un criterio definitivo delimitador de la competencia. Aunque a través de las fórmulas cooperativas puede haberse llegado a un acuerdo de a quien corresponde su realización y su financiación.

Del texto reglamentario puede deducirse que, por lo general, esas infraestructuras básicas, se refieren a obras de regulación pero no 
necesariamente ${ }^{49}$ ( «sistemas de explotación que hacen posible la oferta del recurso"). ¿Todas las obras de regulación (embalses) deben incluirse entre las infraestructuras básicas sea cual sea su dimensión? Puede sostenerse que todas no, sólo aquellas que determinan significativamente la oferta de agua, concepto cuya concreción resulta por sí mismo relativo en función del horizonte espacio-temporal que se contemple 50. A sensu contrario, pueden existir obras que no influyan significativamente en la oferta de agua (que sean infraestructuras no básicas, como señalaba el F.J. 20 e) de la STA $227 / 1988$, de 29 de noviembre, o que recogiéndose en el Catálogo no se declaran de interés general), que tengan interés regional y sean, por ello, de competencia de las Comunidades Autónomas. Se intuye en todo caso, la estrechez de ese espacio ${ }^{51}$ (cualquier dotación seria para un plan de riegos, abastecimiento de una gran ciudad, quedaría excluida) que únicamente puede venir ensanchado como consecuencia de una eficaz política de colaboración interadministrativa.

Junto a las infraestructuras básicas, el Plan puede incluir:

"otras infraestructuras que, por su relevancia, interés social o impacto sobre el medio ambiente o la conservación del entorno, se estime oportuno tomar en consideración».

En conclusión, en el Plan Hidrológico de cuenca debe figurar un catálogo de las obras hidráulicas que tengan la característica de infraestructuras básicas, parte de las cuales o todas (según la flexibilidad o rigidez con la que se interprete el concepto de infraestructuras básicas) son susceptibles de ser declaradas de interés general del Estado (decisión discrecional que corresponde al Gobierno de la Nación en el

\footnotetext{
49 Es indudable que obras hidráulicas que no son de regulación (un canal, una gran tubería de abastecimiento en alta, etc.) pueden entrar en la definición de infraestructuras básicas en cuanto «sistemas de explotación que hacen posible la oferta de recursos». Como puede comprobarse la capacidad expansiva del concepto "infraestructuras básicas» es considerable, si bien carece de eficacia, ya lo he dicho en el texto, como instrumento delimitador último de la competencia sobre obras hidráulicas, que reside en la decisión discrecional del Gobierno de la Nación de declarar una obra de interés general. El problema en el fondo es el de la responsabilidad financiera sobre las mismas y la posibilidad de que gracias a ellas puedan las Comunidades Autónomas obtener reservas de agua para finalidades específicas.
}

50 Es evidente que un pequeño embalse no puede solucionar los problemas de abastecimiento de todos los usuarios de un tramo de un río, pero que sea totalmente suficiente para una concreta finalidad o población.

51 Lo que a la postre no es un "mal», para las Comunidades Autónomas, pues la competencia sobre la obra lleva aparejada la responsabilidad de financiación. 
momento de elaborar el Plan Hidrológico Nacional al incluirlas en él, aprobándose por ley, art. $44 \mathrm{LAg}$ ). Las no declaradas de interés general, podrán ser de interés regional, propias del Organismo de cuenca, propias de las Comunidades de Usuarios o de Corporaciones Locales.

Dificultad de encontrar criterios claros de delimitación para determinar el contenido de la competencia que en materia de obras hidráulicas corresponde a las Comunidades Autónomas ex art. 148.1.10 $\mathrm{CE}$, espacio competencial que, en todo caso, debe existir y respetar el Estado, como así lo señala la STC 227/1988. de 29 de noviembre, F.J. 22, a) 52.

Todavía quedan por analizar dos extremos que permiten constatar, no podía ser de otra manera, la existencia de obras hidráulicas regionales, pero también aquí sigue existiendo la misma indeterminación. El primero de ellos lo recoge el art. 77 RAPA al referirse al concepto de reservas de agua, extremo que obligatoriamente deben recoger los Planes Hidrológicos de cuenca art. 40.d LAg). Según dicho precepto:

"se entiende por reserva de recursos la correspondiente a las asignaciones establecidas en previsión de las demandas que corresponde atender con las obras hidráulicas específicas cuya realización sea de la competencia de la Administración Pública, del Estado o de las Comunidades Autónomas, o por fines de utilidad pública".

Reténgase el dato: «Obras hidráulicas específicas... competencia de las Comunidades Autónomas", lo que permite, y ello es también muy significativo, establecer en el Plan Hidrológico de Cuenca (art. 41.1.LAg, en relación con el 89 RAPA) una reserva ${ }^{53-54}$ de recursos para una demanda

\footnotetext{
52 Señala el Tribunal que «en los demás casos (se refiere a las cuencas intercomunitarias), el Estado puede regular el uso y aprovechamiento de las aguas continentales, siempre que se salvaguarden las competencias asumidas por las Comunidades Autónomas en materia de proyectos, construcción y explotación de los aprovechamientos hidráulicos, canales y regadíos de su interés, así como las demás que ostenten sobre materias conexas, cuando haya de darse prioridad a otros títulos competencias". Pero, adviértase, en ningún momento de la sentencia señala el Tribunal, pues tampoco se cuestiona ello directamente, el contenido competencial derivado del art. 148.1.10 ${ }^{\circ} \mathrm{CE}$. En el mismo sentido DELGADO PIQUERAS, ob. cit., p. 278.
}

53 La relación problemática entre reservas de aguas, Administración competente para crearla y su posible disposición por las Comunidades Autonomas, lo resuelve la STC $227 / 1988$, de 29 de noviembre, en relación a la constitucionalidad del art. 57.5 en relación con el 41.1 y $53.3 \mathrm{Lag}$. Dice así el F.J. 23, j): «los preceptos que ahora se cuestionan impiden el ejercicio de las potestades que las Comunidades Autónomas tienen atribuidas al respecto. Antes bien, el art. $\mathbf{5 7 . 5}$ se limita a facilitar al Estado y a las Comunidades Autónomas el acceso al uso de las aguas en general sin necesidad de concesión previa, mientras que los arts. 41.1 y 53.3 se refieren a reservas de agua o caudales reservados por los planes hidrológicos o por los planes del Estado, pero sin predeterminar en el primer 
determinada (por ejemplo, abastecimiento de una población, plan de riegos, protección medioambiental de la riqueza piscícola de un río, etc.). ¿Quién crea la reserva? El Plan Hidrológico de cuenca que aprueba el Gobierno de la Nación. ¿Motivo de su creación? Atender demandas a las que pueda satisfacerse por la realización de obras específicas estatales o regionales. ¿Quién y cómo dispone de la reserva? El Organismo de cuenca según lo previsto en el art. 77.2 RAPA. En definitiva la realización de obras hidráulicas de interés regional pueden conllevar el reconocimiento de una reserva de aguas con destino a una finalidad específica, reconocimiento que podría tramitarse por el procedimiento de las autorizaciones especiales previsto en el art. 57.5 LAG 55.

Por supuesto que esa competencia regional para la ejecución de obras hidráulicas específicas reconocida en el art. 77.1 RAPA es absolutamente indiscutible en el caso de las Comunidades Autónomas que tengan cuencas intracomunitarias, salvo que el Estado haya declarado esa obra de interés general. Pero no veo inconveniente para que también pueda predicarse de las Comunidades Autónomas en las cuencas intercomunitarias. El problema en este caso vuelve a ser el mismo que se ha constatado: la inexistencia de un criterio delimitador.

caso la autoridad competente para crear la reserva, que lógicamente debe ser la que elabore y apruebe, en los términos señalados, el plan hidrológico, ni excluir en el segundo que puedan existir caudales reservados en planes elaborados por las Comunidades Autónomas".

$54 \mathrm{El}$ dato, digo, es muy valioso, puesto que la reserva no implica necesariamente que quien vaya a disponer de ella sea la Comunidad Autónoma, pero que se inscribirá en el Registro de Aguas a nombre del Organismo de cuenca (hay que entender que en el caso de las cuencas intracomunitarias del órgano gestor regional), «el cual procederá a su cancelación parcial a medida que se vayan otorgando las correspondientes concesiones", puesto que en las cuencas intercomunitarias la disposición de los recursos, su aprovechamiento, corresponde al Organismo de cuenca. Unase esto a la autorización especial otorgada por los Organismos de Cuenca a favor del Estado o de las Comunidades Autónomas (pero sin el trámite concesional, aunque sin perjuicio de terceros) suficiente para acceder a la utilización del agua, prevista en el art. 57.5 LAg y reproducido en el art. 97.2 RDPH y tendremos justificada y explicada la existencia de esas reservas de recursos a favor de una Comunidad Autónoma obtenida con motivo de la ejecución de una obras hidráulica específica. Pero adviértase, la virtualidad de estas reservas a favor de las Comunidades Autónomas, queda hipotecada a la posibilidad de que existan esas obras hidráulicas específicas de su competencia. Sobre el carácter prioritario de las autorizaciones especiales previstas en el art. 57.5, véase DELGADO PIQUERAS, ob. cit., p. 286.

55 Adviértase que el art. 97.2 RDPH se limita a transcribir el párrafo 5 del art. $57 \mathrm{LAg}$. Sería conveniente un mayor desarrollo reglamentario para concretar el alcance y procedimiento y finalidad de estas autorizaciones especiales, que yo vinculo, en parte, con la existencia de reservas de agua a favor de las Comunidades Autónomas. El tema, como digo, requiere de la aclaración reglamentaria pertinente. 
El segundo de los datos viene recogido en el art. 126 del RDPH, dentro de la sección relativa a la tramitación de concesiones de obras e instalaciones en el dominio público hidráulico, procedimiento que se aplica tanto a las obras de defensa, encauzamiento o limpieza de cauces (art. 126.a RDPH) como a las obras de corta, cobertura de cauces, puentes y pasarelas $\mathrm{u}$ otras modificaciones no incluidas en el apartado anterior (art. 126.b RDPH). Ninguna referencia a otras obras hidráulicas (tengan o no la condición de infraestructuras básicas). Pero en el art. 126.3 RDPH se contiene una importante salvedad:

«no necesitarán la concesión a que se refiere este artículo las obras que realice el Estado o las Comunidades Autónomas, incluidas en planes que hubieran sido informados por el Organismo de cuenca y hayan recogido sus prescripciones".

Nótese que no se refiere específicamente a obras hidráulicas, sino, en general a "obras» (por ejemplo, la construcción de una carretera para la que se precisa realizar obras sobre el dominio público hidráulico). No distingue expresamente qué ocurre con las obras de defensa, encauzamiento, promovidas por las Comunidades Autónomas, a las que les ha sido transferida dicha competencia. No dice si, en este caso, deben necesariamente presentarse incluidas en un plan que, previamente, debe ser informado por el Organismo de cuenca para quedar excepcionadas de la necesaria concesión ${ }^{56}$. Quedan sin resolver importantes problemas procedimentales e, incluso, sigue ignorándose la cuestión de la delimitación competencial en relación con las obras hidráulicas 57.

\footnotetext{
56 Parece evidente que la Comunidad Autónoma no puede, sin más trámites, comenzar a ejecutar una obra hidráulica sin que previamente conozca e informe el Organismo de Cuenca en todos sus aspectos (técnicos, de seguridad, etc.), pero no parece que pueda extenderse la competencia de éstos a "aprobar» el proyecto técnico elaborado por la Comunidad Autónoma, en definitiva, a "autorizar» la obra.

57 Todos estos problemas competenciales y procedimentales, unidos a la cuestión anteriormente planteada de las posibles reservas de agua a favor de las Comunidades Autónomas (posible, según he defendido a través de la autorización especial prevista en el art. $57.5 \mathrm{LAg}$ ), en relación con el $77 \mathrm{RAPA}$, se plantean y no se resuelven adecuadamente, en mi opinión, en la S. del Tribunal Superior de Justicia de Aragón, de 22 de diciembre de 1989 (Actualidad Administrativa,@ 123,núm. 6, junio 1990) en relación con la impugnación presentada por Castilla-León, la Diputación Provincial de Burgos y el Ayuntamiento de Tormantos, contra acuerdo de la Confederación Hidrográfica del Ebro autorizando a la Consejería de Obras Públicas del Gobierno de La Rioja la construcción de la presa del embalse de Leiva en los términos municipales de Leiva y Tormantos (La Rioja), en el cauce del río Tirón. En ella se considera la obra de interés regional (pues no lo es de interés general ni afecta a otra Comunidad, según los informes técnicos), necesitada de autorización, lo que no conlleva la concesión de los caudales que se embalsen, para los que en su día deberá tramitarse la oportuna concesión.
} 
En todo caso, conviene tener presente que en relación con un tipo de obras, las de las entidades locales, se han dado pasos hacia la clarificación en cuanto a la delimitación competencial, como consecuencia del juego del ejercicio del título competencial sectorial correspondiente así como del relativo a "régimen local». En este sentido, se han considerado de interés regional determinadas fases de las obras hidráulicas relativas al abastecimiento y saneamiento (Comunidad de Madrid 58 o, Cataluña 59) o sujetas a Planes Directores de Coordinación (Navarra ${ }^{60}$ ), que aprueba la Comunidad Foral. En otros casos, algunas de las competencias transferidas a las Comunidades Autónomas en materia de obras hidráulicas han sido, a su vez, delegadas en las Diputaciones Provinciales 61. Materias, como puede fácilmente deducirse, tradicionalmente municipales en las que ha existido una importante línea de auxilios financieros por parte del Estado, ahora, sustituido por las Comunidades Autónomas.

Señalar, por último, que tampoco aporta solución definitiva al problema de la delimitación competencial en relación con las obras hidráulicas de

58 Es el caso de la pionera ley madrileña $17 / 1984$, de 20 de diciembre, reguladora del abastecimiento y saneamiento del agua que dentro del abastecimiento distingue los servicios de aducción y distribución (art. 1.2) y en el saneamiento los de alcantarillado y depuración (art. 1.3) para considerar de interés y competencia de la Comunidad de Madrid los de aducción y depuración y de competencia municipal los de distribución de agua y alcantarillado. Esta operación, que pudiera considerarse colisiona con las previsiones del art. 25.2 y 26 LRBRL, en cuanto que reservan a los municipios como servicios esenciales el abastecimiento y saneamiento, la considero perfectamente legítima, desde el punto de vista constitucional de respeto a la autonomía local. Un análisis de la ley puede verse en MORELL OCAÑA, «Abastecimiento...» ya citado.

59 La ley 4/1990, de 9 de marzo, de ordenación del Abastecimiento de Agua en el Area de Barcelona, siguiendo con la filosofía de la ley madrileña, declara como servicio público de interés de la Generalidad la producción y suministro de agua potable para abastecimiento mediante la red básica de abastecimiento (art. 4, en relación con el 2.2). Sin embargo constituye un servicio mínimo de competencia municipal el abastecimiento domiciliario de agua potable incluidas de redes secundarias (art. 3 en relación con el 2.3). En relación con este problema concreto así como en relación a la legislación hidráulica de Cataluña, véase la conferencia de E. ARGULLOL MURGADAS, "Cataluña y su legislación en materia de aguas», Legislación..., pp. 120-143.

60 Ley Foral 10/1988, de 29 de diciembre, de saneamiento de aguas residuales de Navarra. Según el art. 2 de dicha ley corresponde a la Comunidad Foral la aprobación definitiva de los distintos planes y proyectos técnicos de ejecución de obras de depuración de aguas residuales y de explotación de los servicios.

61 Es el caso de Aragón. La ley 8/1985, de 20 de diciembre, reguladora de las relaciones con las Diputaciones Provinciales, les delega a éstas la competencia para «aprobar y tramitar las inversiones en las obras de interés de la Comunidad Autónoma en materia de abastecimiento y distribución de aguas y redes de saneamienton. Dichas obras han sido incluida entre los objetivos prioritarios de los Planes Provinciales de Obras y Servicios de las Diputaciones Provinciales aragonesas. 
interés regional la doctrina del Consejo de Estado ${ }^{62}$. Debe advertirse que el Consejo de Estado identifica claramente el concepto de «aprovechamientos" utilizado en el art. 148.1.10 $\mathrm{CE}$ con el de "obras hidráulicas» 63. Para el Consejo de Estado no caben incompetencias regionales sobre obras hidráulicas en aguas supracomunitarias. ¿Cómo dotar de contenido ese título competencial derivado del art. 148.1.10 $\mathrm{CE}$ ? A este propósito señala el supremo órgano consultivo que:

«el Estatuto de Autonomía de Extremadura no quiere que la Comunidad Autónoma asuma competencias sobre obras en aguas intercomunitarias, siempre y cuando dichas aguas mantengan tal carácter. De ahí que sea preciso determinar únicamente si el agua ha dejado de ser o no supracomunitaria, debido a una previa disposición estatal sobre la misma; analizar si, una vez dispuesta esa agua por el Estado la misma no saldrá de la Comunidad; analizar si la obra a ejecutar se efectúa dentro del territorio de la propia Comunidad Autónoma y observar finalmente si la obra en sí misma no es de interés supracomunitario»

La influencia de las tesis defendidas por Menendez Rexach 64 en este dictamen salta a la vista. Pese a lo que parezca, la tesis es restrictiva de las competencias regionales en cuanto imposibilita la realización de obras hidráulicas que afecten al recurso (por ejemplo, la ejecución de obras de regulación). Lo curioso es que aquí la defensa de la competencia regional, tiene la consecuencia negativa para la Junta de Extremadura de que debe hacer frente al pago de las subvenciones correspondientes, a lo que ella se oponía por considerar que era una obra de interés general y carecer de la necesaria dotación presupuestaria. En efecto, con arreglo a dicha doctrina el Consejo de Estado establece que

62 Me refiero al dictamen núm. 49947, Sec. 6ª , Obras Públicas y Urbanismo, de 30 de abril de 1987 Rec. Doctrinal Legal, 1987, § 17. Aunque figura otro dictamen en el $\S 19$, parece que es el mismo, por el número de dictamen y la fecha, aunque hay parte del texto que no coincide.

63 Señala que "es sólo el art. 148.1.10 (no atribuido de competencias al Estado) el que se refiere a obras hidráulicas», pág. 69, último párrafo de la recopilación legal de 1987.

64 Recuérdese que MENENDEZ REXACH distingue entre obras hidráulicas de aprovechamiento (abastecimiento, riegos, etc.) competencia de las Comunidades Autónomas si el caudal aprovechado discurre íntegramente por la Comunidad Autónoma (criterio que rechazábamos como contrario al principio de unidad de gestión, y así lo ha hecho la STS de 17 de julio de 1990) y obras hidráulicas distintas de los aprovechamientos (de regulación, de encauzamiento, defensa, etc.) que en cuanto ligadas al recurso son competencia siempre en las cuencas intercomunitarias del Estado, salvo que se lo atribuya la legislación estatal. Sin embargo, advierte MENENDEZ REXACH, esta interpretación es difícil de armonizar con los Decretos de traspasos de servicios, por lo que concluye que «el tema requiere una urgente clarificación», p. 590. 
corresponde a la Comunidad el pago de las subvenciones previstas en la Ley Gasset, en relación con unas obras de transformación en regadío al ser la obra competencia de dicha Comunidad 65 .

Tampoco resuelve el problema que se viene examinando la tesis defendida por Delgado Piqueras ${ }^{66}$, por partir de un a priori que precisamente es el que se trata de precisar. Para este autor la virtualidad del título competencial derivado del art. $148.1 .10^{\mathrm{a}} \mathrm{CE}$ se pone en juego en el momento de la planificación hidrológica. De ahí que, «el respeto de las competencias autonómicas en esta materia exige una prevalencia de los proyectos diseñados con el carácter de interés comunitario, de manera que dichas propuestas deberán ser obligatoriamente recogidas en los planes hidrológicos, a salvo, claro es, que a ello se oponga el interés nacional, una incompatibilidad entre proyectos de distintas Comunidades Autónomas, que habría que armonizar en función del interés general, o una imposibilidad material, motivos todos ellos que habrá que razonar y, sobre todo, podrán ser contrastados en las instancias oportunas» ${ }^{67}$. Adviértase, sin embargo, que lo que sigue sin resolverse es el criterio de delimitación competencial acerca de las obras hidráulicas.

En conclusión final, la competencia en materia de obras hidráulicas de interés regional está en función de lo que diga la Administración del Estado en cuanto a las obras que el Gobierno de la Nación considere de interés general. Facilitaría la delimitación de uno y otro campos que en el proceso de elaboración de los Planes hidrológicos de cuenca se recogiera una propuesta (que debería estar previamente pactada) de calificación de las distintas obras de infraestructura hidráulica (las de interés general, las regionales, las propias del Organismo de cuenca, las de las Comunidades de usuarios, las de las Corporaciones locales). Contribuiría a esa necesaria delimitación y a la consiguiente propuesta, que las instrucciones y recomendaciones técnicas que puede aprobar el Ministerio de Obras Públicas y Transportes (art. 88 RAPA), para homogeneizar y sistematizar los trabajos relativos a la elaboración de los Planes Hidrológicos, incluyeran criterios para la declaración de una obra hidráulica como de interés general.

\footnotetext{
65 Recuérdese la doctrina de la STC 13/1992, de 6 de febrero, que considera inconstitucional la retención por el Estado de dotaciones presupuestarias que corresponden a competencias asumidas por las Comunidades Autónomas y que el Estado debe territorializar convenientemente.
}

66 DELGADO PIQUERAS, ob. cit., p. 278-280.

67 Ibíd. pp. 279-280. 


\section{FORMAS INSTITUCIONALES DE COOPERACION}

En definitiva, ante la elasticidad del concepto «infraestructura básica» y la discrecionalidad del Gobierno de la Nación para declarar parte de estas como obras de interés general (aspectos de los que depende la sustantividad de las obras hidráulicas de interés regional), no queda otra vía que la ya apuntada de apurar los cauces de la cooperación a través de los correspondientes convenios interadministrativos, así como sacar todas las potencialidades a la incorporación de las Comunidades Autónomas a los órganos de las Confederaciones Hidrográficas (art. 23 LAg.), precepto cuya importancia ha destacado Embid Irujo en su conferencia. Vía de colaboración pluridireccional, decía más arriba, en la que se impliquen todos los sujetos afectados (Administración del Estado, Comunidades Autónomas, Organismo de Cuenca, Corporaciones Locales, Comunidades de Usuarios). Pero respeto de unas reglas de juego por parte del Estado que debe mantener una equilibrada posición como garante de los intereses generales (territorialización proporcional del gasto público en materia de obras hidráulicas). Respeto, también de unas formas procedimentales donde quede constancia de la naturaleza de las obras y actuaciones que se han de acometer (si son de interés general, regional, etc.) y se dé entrada a todos los sujetos afectados.

\section{1) Los convenios de colaboración}

Examinemos alguna manifestación de las fórmulas de cooperación en el ámbito de la Cuenca Hidrográfica del Ebro. Me refiero al Acuerdo de colaboración suscrito entre el MOPU (ahora Transportes) y la Comunidad Foral de Navarra el 19 de octubre de 1988 y al muy reciente Convenio de colaboración, de 8 de febrero de 1992, relativo a la mejora de infraestructuras y aprovechamientos hídricos del Canal de Piñana, suscrito por el Ministerio de Obras Públicas y Transportes, la Diputación General de Aragón, la Generalidad de Cataluña, la Comunidad General de Regantes del Canal de Piñana, los productores de energía hidroeléctrica y la Comunidad de Regantes del Canal Algerri-Balaguer. Advierto que el análisis que hago de estos dos convenios obedece a una lectura estrictamente formal y jurídica de los mismos, preocupado por la búsqueda de un criterio delimitador de las obras hidráulicas regionales/generales. Dejo al margen, pues, toda valoración política, que por supuesto no debe desconocerse ${ }^{68}$. Analicemos cada uno de ellos.

\footnotetext{
68 A la II Jomadas sobre Derecho de las Aguas, asistió una representación de todas las fuerzas parlamentarias de Navarra, encabezados por el Presidente del Parlamento, que tuvo la ocasión de explicar el apoyo mayoritario de dichas fuerzas políticas al Convenio suscrito con el Ministerio.
} 
En el R.D. 1391/1988, de 18 de noviembre, de traspaso de servicios del Estado en materia de obras hidráulicas, se establece en relación con aquellas funciones concurrentes y compartidas entre Administración del Estado y Comunidad Foral la posibilidad de «colaborar, mediante los oportunos acuerdos, en el desarrollo de estudios, ejecución y gestión de obras e instalaciones" (Apartado 4.c). Fórmula del acuerdo, del convenio. Pero prosigue dicho apartado:

"A este respecto se considerarán en los planes hidrológicos del Ebro y del Norte, las propuestas resultantes de los estudios que está desarrollando actualmente el Gobierno de Navarra para la elaboración de la planificación hidrológica en lo que afecta a su territorio".

Parece evidente que esa "propuestas» del Gobierno de Navarra, aunque la redacción literal no sea muy correcta 69 , deben ser recogidas en el acuerdo correspondiente con la Administración del Estado. Esto es, no pueden tener eficacia inmediata ante el Organismo de cuenca, si no media esa previa formalización.

Pues bien, al día siguiente de la firma del acuerdo de la Junta de transferencias de servicios (18 de octubre de 1988) se firma un Acuerdo de colaboración (19 de octubre de 1988) entre el, entonces, MOPU y la Comunidad Foral de Navarra, en materia de obras hidráulicas por el que el MOPU se compromete a financiar la totalidad de las obras de cuatro presas, siendo de cuenta del Gobierno de Navarra el pago de los terrenos necesarios para su ejecución. Pero lo significativo, desde mi punto de vista, es la fundamentación del acuerdo:

"considerando que ambas partes estiman de gran interés y necesidad la ejecución de una serie de obras que afecta a la regulación de la cuenca del Aragón, cuya influencia sobrepasa los límites de Navarra y que permitirán, entre otros aprovechamientos, la transformación en regadíos de amplias zonas de la Comunidad Foral»

¿Qué sentido tiene hablar de "gran interés y necesidad"? ¿Por qué no se habla de interés general o nacional puesto que se reconoce que su influencia sobrepasa los límites de Navarra? ¿Se consideran dichas obras infraestructuras básicas de interés general? ¿Acaso no sería necesario un marco más amplio para un acuerdo de este tipo, puesto que la cuenca del Aragón no es, en absoluto, intracomunitaria e, incluso, una de las presas se construirá sobre el mismo río Ebro para derivar aguas

${ }^{69} \mathrm{Su}$ interpretación literal, dejando a una de las partes la posibilidad de que sus propuestas sean recogidas en la planificación hidrológica del Ebro y del Norte sería inadmisible, en mi opinión, desde una perspectiva jurídica. 
a la cabecera del río Arga? Y nótese, ya lo he dicho, que las propuestas resultantes de este acuerdo "se considerarán en los planes hidrológicos de las cuencas del Ebro y del Norte». En definitiva, siguen sin resultar claros los criterios para delimitar la competencia de las distintas Administraciones en materia de obras hidráulicas, fuera del compromiso concreto de cofinanciar determinadas obras hidráulicas.

Un sentido distinto tiene el Convenio de colaboración relativo a la mejora de infraestructuras y aprovechamientos hídricos del Canal de Piñana. No sólo se refiere a la construcción de obras hidráulicas sino que se acuerda modificar el destino actual de ciertos aprovechamientos. También en él se hace referencia a que las partes lo estiman «de gran interés y necesidad... cuya influencia sobrepasa los límites de Aragón». Sin embargo, aquí se da una amplia participación a todos 70 los intereses afectados. Sin duda alguna, este convenio de colaboración constituye un primer paso de lo que debe ser un modelo de actuar global y permanente, aplicado no sólo a la regulación de un río o de un aprovechamiento, sino al ámbito de toda la cuenca.

En definitiva, debe superarse la fase de "victimismo" 71 practicada en algunos momentos por los representantes de algunas Comunidades $\mathrm{Au}$ tónomas y hay que acudir a los foros adecuados con voluntad de aportar soluciones y "dinero", siendo conscientes de la importancia vital de un recurso como el agua para el desarrollo futuro de cada Comunidad Autónoma, apreciando en toda su dimensión el valor de estas fórmulas cooperativas así como la participación de los representantes de las Comunidades Autónomas en los Organismos de cuenca, de la que paso a ocuparme.

\section{2) La incorporación de las Comunidades Autónomas a los Orga- nismos de Cuenca}

La práctica ausencia de competencias de las Comunidades Autónomas pertenecientes a cuencas intercomunitarias en materia de aguas, con la

\footnotetext{
70 También en el coloquio que siguió a la conferencia de E. ARGULLOL, antes citada, se cuestionó por los representantes de Comunidades de Regantes (el de Bardenas, en particular) la falta de conocimiento del contenido del citado pacto por todos los regantes afectados y en particular que no se informara del mismo a la Junta de Gobierno de la Confederación Hidrográfica del Ebro.

71 Véase como un reflejo de este espíritu, el inicio del Decreto aragonés 136/1988, de 19 de julio, cuyas primeras palabras son del siguiente tenor: "La crónica desatención que viene sufriendo históricamente una amplia parte del territorio de Aragón por los poderes públicos del Estado...", durante el Gobierno regionalista de H. Gómez de las Roces.
} 
salvedad de la imprecisa relativa a las obras hidráulicas de interés regional, obliga a destacar la importancia institucional que para ellas tiene su incorporación a los Organismos de Cuenca, en particular a la Junta de Gobierno (art. 23 y 25 LAg y 29 y ss. RAPA) y al Consejo del Agua (art. 33 LAg y 53 y ss. RAPA). Los Decretos constitutivos de cada una de las Confederaciones fijan el número de representantes que corresponden a cada Comunidad Autónoma en dichos órganos. Participando en dichos órganos, participan en la gestión y administración del dominio público hidráulico. El tema da de sí para unas futuras Jornadas. Sólo quiero apuntar dos aspectos de esta problemática, advirtiendo que se trata de opiniones personales, expresadas desde la seriedad y que no quieren ser un estímulo gratuito a la demagogia.

El primero de ellos hace referencia a la determinación de la representación de cada Comunidad Autónoma 72 . En la Junta de Gobierno se garantiza la presencia de, al menos, un representante por Comunidad ${ }^{73}$, distribuyéndose el resto "en función del número de Comunidades Autónomas integrantes de la cuenca y de la superficie y población de las mismas en ella comprendidas", (art. 25. d LAg). Cabría preguntarse si estas dos variables (superficie y población) reflejan adecuadamente la implicación de una Comunidad en la respectiva cuenca hidrográfica ${ }^{74}$. ¿Acaso debiera tenerse en cuenta como tercera variable, la capacidad regulada ubicada en cada Comunidad $\left(\mathrm{Hm}^{3}\right)^{75}$, para primar aquellas

$72 \mathrm{Al}$ referirme en un epígrafe anterior a los Derechos de traspasos de competencia en materia de obras hidráulicas, me he referido a que ya en ellos se preveía la incorporación de representantes de las Comunidades autónomas a las Confederaciones Hidrográficas. Véase la nota 40.

73 Criterio laudable, pero que en algún caso puede resultar disfuncional. ¿Qué ocurre cuando el territorio de una Comunidad no represente siquiera el $2 \%$ del territorio de una cuenca hidrográfica? ¿No justificarían supuestos como el descrito que se establezcan techos necesarios de implicación ( $5 \%$ o el que se estime, siempre que la capacidad regulada ubicada en ese escaso territorio no supere determinada capacidad)?

74 La representación de las Comunidades Autónomas en la Junta de Gobierno de la Confederación Hidrográfica del Ebro es la siguiente: Aragón, 6 representantes; Cantabria, 1; Castilla y León 1; Cataluña, 3; La Rioja, 2; Navarra, 2; País Vasco, 1; Valencia, 1. En resumen, 17 representantes de un total de 44. La del Consejo del Agua es la siguiente: Aragón, 12; Cataluña, 6; Navarra, 4; La Rioja, 4; Cantabria, 2; Castilla y León, 2; Castilla-La Mancha, 1; País Vasco, 2 y Valencia, 1. En resumen, 34 representantes de un total de 80.

75 Téngase en cuenta que Aragón, por ejemplo, según los datos publicados, en 1983, por la Dirección General de Obras Hidráulicas relativos al Plan Hidrológico del Ebro, aporta el $50 \%$ natural de caudales y supone el $70 \%$ aproximadamente de la regulación total del Ebro, tanto en demanda modulada como continua,. Tomo los datos de J.A. BAGUENA SANCHEZ, "La economía aragonesa en el eje del Ebro», Papeles de Economía Española, núm. 10 (1991), «Economía de las Comunidades Autónomas: Aragón». 
Comunidades que soportan en su territorio grandes superficies inundadas que benefician a toda la cuenca?

Segundo problema que también sólo quiero apuntar, pues este sí tiene más entidad. El reparto de funciones entre los diferentes órganos que integran la estructura organizativa interna del Organismo de cuenca, ¿da cumplida respuesta a la inexistencia de competencias de las Comunidades Autónomas que pertenecen a cuencas intercomunitarias sobre los recursos y que, por ello, su participación en la gestión del agua se canaliza, casi en exclusividad, a través de su incorporación al Organismo de cuenca?

Cierto que, en la actualidad, se ha materializado el principio de gestión unitaria de los recursos hidráulicos por la integración de las funciones ("funciones de soberanía del Estado en materia de aguas públicas», contrapuestas a las "funciones confederales de formación de planes, ejecución y explotación de las obras y prestación de servicios», según el Decreto de 8 de octubre de 1959) de las Comisarías de Aguas. Pero en dichas funciones "administrativas", de "soberanía", no existe participación de las Comunidades Autónomas ${ }^{76}$ ni de los usuarios, por la integración de la Comisaría en la estructura organizativa de la Presidencia de la Confederación (R.D. 984/1989, de 28 de julio) y corresponder al Presidente la "superior función directiva y ejecutiva del Organismo" (art. 28.d LAg) que incluye, entre otras, la de "otorgar concesiones y autorizaciones de aprovechamiento del dominio público hidráulico (32.2.f RAPA).

¿Acaso debiera reflexionarse sobre este reparto interno de funciones, que desplaza a la representación de las Comunidades autónomas y Usuarios 77 de importantes decisiones? Tal vez pueda defenderse que esa exclusión constituye una exigencia impuesta por el principio recogido en el art. 22 fine $\mathrm{LAg}$ que señala que:

«en la determinación de la estructura de los Organismos de cuenca se tendrá en cuenta el criterio de separación entre las funciones de administración del dominio público hidráulico y las demás».

\footnotetext{
${ }^{76} \mathrm{Su}$ participación en el procedimiento de otorgamiento de concesiones de dominio público hidráulico está prevista en el art. $110 \mathrm{RDPH}$, pero ese informe no lo es en el aspecto relativo a la gestión del recurso (aunque excepcionalmente puedan tenerla, como es el caso de la concesión de un caudal en una zona húmeda declarada por la Comunidad reserva natural y en la que esté prohibida dicha extracción), sino a los otros que tienen que ver con la competencia de la Comunidad.
}

$77 \mathrm{Al}$ presidente corresponde no lo que serían simples funciones de dirección y ejecución sino entre otras, aprobar el Plan de actuación, ejercer la facultades de contratación, autorizar gastos, aprobar los proyectos ténicos de obras, etc. 
Pero que deba existir esa separación no implica necesariamente que se excluya de ellas, como queda dicho, particularmente a las Comunidades Autónomas, pues es difícil negarles su condición esencial de Administraciones Públicas. Distinta se presenta la exclusión, más justificada, en el caso de los usuarios (no cabe pensar que las funciones «administrativas» de control y policía se encomienden a los propios interesados). El tema es delicado y no conviene dar pábulo a planteamientos demagógicos. Quede simplemente planteado el interrogante.

\section{LA ORGANIZACION ADMINISTRATIVA DE LAS COMUNIDA- DES AUTONOMAS EN RELACION CON LAS AGUAS}

El escaso margen competencial al que quedan reducidas las competencias en materia de aguas de las Comunidades analizadas, tiene su repercusión en cuanto a la organización administrativa hidráulica: no existe propiamente una Administración Hidráulica regional (general, en la terminología empleada por Embid Irujo, en su conferencia), como autoriza el art. $16 \mathrm{LAg}$ para el caso de aquellas Comunidades Autónomas con cuencas intracomunitarias. Que no exista una Administración Hidráulica propia no quiere decir que no existan unos servicios administrativos que con más o menos realismo tienen encomendadas las competencias sobre recursos y obras hidráulicas que he señalado.

En Cantabria, integrada en la Consejería de Obras Públicas, Vivienda y Urbanismo, se ha creado recientemente una Dirección Regional de Obras Hidráulicas ${ }^{78}$. En La Rioja, integrada en la Consejería de Obras Públicas y Urbanismo, existe una Dirección General de Obras Públicas y Transportes, a la que corresponde la «planificación y ejecución de la política del Gobierno en materia de obras hidráulicas" 79 .

En Aragón, integrada en el Departamento de Ordenación Territorial, Obras Públicas y Transportes, existe una Dirección General de Obras Hidráulicas ${ }^{80}$. La preocupación aragonesa por las cuestiones hidráulicas se manifiesta ya en la fase preautonómica en la que se crea, por

78 Creada por D. 122/1991, de 18 de julio.

79 Véase el D. 41/1988, ed 7 de octubre por el que se modifica la estructura orgánica y funcional de la Consejería de Obras Públicas y Urbanismo, plenamente respetuoso al enumerar las funciones sobre obras hidráulicas con las competencias estatutarias asumidas.

80 La estructura de las actuales Direcciones Generales es la resultante del D. 136/1991, de 2 de agosto entre las que figura la de la Dirección General de Obras Hidráulicas, desarrollada por el D. 122/1992, de 7 de julio, por el que se aprueba la estructura orgánica del Departamento de Ordenación Territorial, Obras públicas y Transportes. 
Decreto de 26 de diciembre de 1978, la Comisión Interdepartamental de los Riegos y Aguas, a la que se le atribuyen, con poco realismo, unas funciones muy ambiciosas. Aprobado el Estatuto de Autonomía, se crea, por D. 76/1983, de 21 de julio la Comisión Interdepartamental de Recursos Hidráulicos. En la actualidad, se ha querido hacer del Departamento de Ordenación Territorial, Obras Públicas y Transportes el centro gestor de cuantas actividades «tiene atribuidas la Comunidad Autónoma de Aragón o con las que deben atribuirsele en materia de aguas, incluidas las subterráneas, minerales y termales, obras hidráulicas, canales y regadíos de interés de dicha Comunidad», las cuales se someterán a informe preceptivo y vinculante de dicho Departamento.

El sistema de designación de los representantes de la Comunidad Autónoma en las Confederaciones del Ebro, Tajo y Júcar, ha sido, con poco realismo (pero indicativo de la importancia que los temas del agua suscitan en Aragón), regulado por la ley 13/1990, de 21 de diciembre. Los representantes en la Junta de Gobierno los nombra el ejecutivo regional, así como los del Consejo del Agua, pero éstos a propuesta de los grupos parlamentarios de las Cortes Aragonesas ${ }^{81}$. Corresponde al Presidente de la Comunidad el nombramiento del representante de Aragón en el Consejo Nacional del Agua.

En cuanto a Navarra, integrada en el Departamento de Obras Públicas, Transportes y Comunicaciones ${ }^{82}$, existe un Servicio de Obras Públicas, al que corresponde la "planificación, gestión y explotación de los recursos hídricos superficiales y subterráneos, excepto aquellas funciones ejercidas por las Confederaciones Hidrográficas, Comisarías de Aguas y Ministerio de Industria y el planteamiento y ejecución de obras hidráulicas que no tengan la calificación legal de interés general del Estado o cuya realización no afecte a otros territorios del mismo". Parece evidente que la fecha de este Decreto, anterior a la LAg 1985, es determinante de la enumeración de las citadas funciones.

Como órgano consultivo y asesor del Gobierno de Navarra en materias relacionadas con el agua, se ha creado, por D. Foral 147/1990, de 31 de mayo un Consejo del Agua de Navarra, en el que están representados los distintos intereses afectados (Administración Navarra, partidos

\footnotetext{
81 Recientemente se ha presentado una proposición de ley (B.O.Cortes de Aragón, núm. 5, de 24 de octubre de 1991), aunque retirada en el momento de someterla a votación, dirigida a modificar este sistema a atribuir, en todo caso, el nombramiento de los representantes de la Comunidad en los Organismos de cuenca al órgano de Gobierno.
}

82 Regulado por D. Foral 47/1984, de 16 de mayo. 
políticos, entidades locales, usuarios de aguas para riego, y aprovechamientos hidroeléctricos).

Finalmente, y en relación a la política de riegos y de saneamiento de aguas residuales, por los D. Forales 67/1984, de 16 de mayo, y 29/1989, de 2 de febrero, se han constituido la sociedad «Riegos de Navarra, S.A.» y la empresa "Navarra de Infraestructuras, S.A. (NILSA), ejemplo de Administración Hidráulica sectorial, en la terminología propuesta por Embid Irujo.

\section{AGUAS MINERALES Y TERMALES}

El sentido de figurar las "aguas minerales y termales» dentro de los títulos específicos no es otro que seguir con la línea doctrinal tradicional que las considera como un recurso mineral. Sin embargo, considero que este planteamiento no es ajustado a la gestión unitaria de los recursos hidráulicos, sin que ello suponga ignorar que es una de las competencias que el art. 148.1.10 $\mathrm{CE}$ atribuye a las Comunidades Autónomas, sin duda siguiendo una interpretación deudora de aquella concepción tradicional. Como queda dicho, constituye una competencia asumida por todas las comunidades (ex art. 148.1.10 $\mathrm{CE}$ ), si bien queda delimitada por la legislación básica estatal de aguas y minas (en aspectos tales como dominio, protección, aprovechamiento), como algunos Estatutos se cuidan de precisar (art. 44.6 LORARFN). A algunos de estos problemas -el de dominio - ya he hecho referencia y a ello me remito. Competencias, pues, legislativas, de desarrollo y prácticamente todas las funciones ejecutivas o administrativas (una excepción la constituye el informe preceptivo previsto en el art. 24.2 LMi del ahora denominado Instituto Tecnológico y Geominero, dependiente del Ministerio de Industria, definitivo para la declaración de la condición del agua como mineral o termal precepto que debe considerarse básico).

Extremo importante, pues de ello deriva que la competencia sobre el aprovechamiento de unas aguas corresponda al Organismo de cuenca o a la Comunidad Autónoma correspondiente, es el de determinar la condición mineral o termal de las aguas. Junto a la previsión recogida en el citado art. 24.2 LMi del informe del Instituto Tecnológico y Geominero (trámite recogido, asimismo, en los arts. 4,5 y 6 del Reglamento cántabro), el art. 1.4 RDPH señala que «en el expediente para su calificación como tales se habrá de oír al Ministerio de Obras Públicas y Transportes a los efectos de su exclusión del ámbito de la ley de Aguas", audiencia que junto a aquel informe parecía resultar necesaria como requisito para evitar de futuro posibles colisiones entre 
aprovechamientos de aguas minerales o termales (de competencia regional) y otros que puedan llegar a afectar a los primeros (de competencia del Organismo de cuenca) ${ }^{83}$.

Sin embargo, la STC 227/1988, de 29 de noviembre (F.J.33), ha considerado que la previsión del art. 1.4 RDPH invade las competencias del País Vasco ${ }^{84}$, extremo que lleva al fallo de la sentencia, pero, dado que la competencia sobre aguas minerales y termales corresponde por igual a todas las Comunidades Autónomas, puede sostenerse la extensión de los efectos de la cosa juzgada a todas las demás. Con todos los respetos por el fallo del Tribunal, considero que aquí no se ha sopesado suficientemente el mecanismo de intervención, pues se desconoce el carácter básico, que he señalado más arriba, debe tener la participación del Instituto Tecnológico y Geominero, extremo distinto del trámite previsto en el art. 1.4 RDPH. Cabría considerar acertado el fallo del Tribunal si al tiempo se salva, considerándola como básica, la participación del citado Instituto.

Sólo Cantabria, entre las Comunidades Autónomas consideradas, ha dictado una ley, la $2 / 1988$, de 26 de octubre de fomento, ordenación y aprovechamiento de los balnearios y de las aguas minero-medicinales y/o termales, desarrollado por el D. 28/1990, de 30 de mayo, que en lo relativo a éstas últimas sigue prácticamente sin cambios las previsiones de los arts, 23 y ss. de la LMi, con las lógicas variantes organizativas 85 . La ley de Cantabria y su reglamento, dedican especial atención a la regulación de los establecimientos balnearios (de las instalaciones balnearias, industriales y hoteleras), los derechos de los usuarios y la creación de una Junta Asesora para estas materias, cuestiones que nos sitúan ante aspectos ya alejados de la problemática de las aguas y que por ello los marginamos conscientemente.

83 Colisión que puede producirse en el llamado perímetro de protección que se fije para el aprovechamiento de agua mineral o termal, según el art. 11 del Reglamento de Cantabria, perímetro al que ya se refería el art. 28 LMI. En efecto, el aprovechamiento de aquellas aguas permite a su titular impedir que se realicen dentro de dicho perímetro de protección trabajos o actividades que pudieran perjudicarlo. Al mismo tiempo sólo da derecho a aprovechar dichas aguas dentro del perímetro y siempre que pertenezcan al mismo acuífero. Los eventuales conflictos suscitados con anterioridad se producían entre MOPU y Ministerio de Industria. Ahora, entre Comunidades Autónomas y Organismos de Cuenca.

84 «La eventual defensa de las aguas de titularidad estatal» queda salvada para el Tribunal mediante la posibilidad de "comparecer como parte interesada en el expediente de calificación $y$ defender sus derechos y competencias en la vía judicial competente conforme a las Leyes generales, F.J. 33.

85 Unicamente quedan fuera de regulación del Reglamento las aguas minero-industriales. 


\section{REFORMA Y DESARROLLO AGRARIO}

Junto a las competencias específicas que corresponden a todas las Comunidades Autónomas en materia de canales y regadíos (obras hidráulicas relativas a los mismos), que incluyen desde los proyectos técnicos (obras hidráulicas) hasta las medidas de apoyo financiero correspondientes, con exclusión de la disposición del agua (sin perjuicio de lo que he señalado sobre las reservas de agua), el título «agricultura» en el que se insertan las actuaciones de "reforma y desarrollo agrario» 86 permite, desde este título específico, un campo de actuación propio a las Comunidades Autónomas. Ello no debe hacernos olvidar que dicha materia es susceptible de entrecruzamiento con otros títulos competenciales, puede ser susceptible de actuaciones estatales (ordenación general de la economía, derecho de propiedad, recursos y aprovechamientos hidráulicos, obras de interés general) y que sean frecuentes las actuaciones concurrentes.

No debe olvidarse, por lo demás, que forman parte del contenido obligatorio de los Planes Hidrológicos de cuenca (art. 40.d LAg.) «las normas básicas sobre las mejoras y transformaciones en regadío que aseguren el mejor aprovechamiento del conjunto de recursos hidráulicos y terrenos disponibles», disposición básica, como ha recordado la STC $227 / 1988$, de 29 de noviembre, que tendrá justificación en cuanto «se propongan estrictamente el logro de un mejor o más racional aprovechamiento de las aguas continentales como recurso económico esencial, y no se extiendan a otras prescripciones sobre la política agrícola" (F.J. 20, apartado e).

\section{1) Aragón}

Esos supuestos de concurrencia a los que me refería se dan en Aragón en relación con las actuaciones declaradas de interés general de la $\mathrm{Na}$ ción en las grandes zonas de transformación agraria por aplicación de legislación de Reforma y Desarrollo Agrario (con sus antecedentes en la Ley de riegos del Alto Aragón, declarada vigente por el TS y de la legislación sobre colonización agraria). El R.D. 643/1985, de 2 de abril, de traspaso de funciones en materia de reforma y desarrollo agrario, tras atribuir a Aragón la competencia para realizar todas las actuaciones de

86 Sobre la cuestión MUÑOZ MACHADO, Derecho Público de las Comunidades Autónomas, Cívitas, T.I. Madrid, 1982, pp. 514 y ss. Este autor ya advertía que en la materia de "reforma y desarrollo agrario", podían incidir otro títulos competenciales estatales como ordenación general de la economía, legislación civil, obras públicas y aprovechamientos hidráulicos (p. 516). 
reforma y desarrollo agrario ${ }^{87}$ de interés para Aragón 88 , sujeta a un régimen de concurrencia con la Administración del Estado, entre otras las «obras públicas y planes de actuación de interés general de la $\mathrm{Na}$ ción o que afecten a más de una Comunidad Autónoma" (Apartado D.4), en cuyo caso Aragón ejecutará las actuaciones de competencia del Estado en la materia que le sea encomendada por éste. Señala, en particular que:

«En cuanto a las zonas actualmente vigentes declaradas de interés nacional, la Comunidad Autónoma ejecutará todas las actuaciones ya planificadas para su ejecución por IRYDA en su territorio. Para los Planes pendientes, el Plan General de Transformación, en su caso, que será aprobado por el Consejo de Ministros, se elaborará con la participación de la Comunidad Autónoma y los planes de obras se aprobarán por ambas Administraciones a propuesta de las Comisiones Técnicas correspondientes. A dichas Comisiones, que adaptarán al efecto su estructura orgánica y funciones, con representación de ambas Administraciones, les corresponderán, igualmente el seguimiento de los planes.

Su ejecución corresponderá de ordinario a la Comunidad y su financiación se realizará por una y/u otra Administración».

Importante implicación de ambas Administraciones en cuanto a la ejecución de los Planes pendientes y sobre todo, importantes consecuencias para lograr su culminación, tanto tiempo esperada (pues no se olvide que algunas actuaciones arrancan de la ley de riegos del Alto Aragón de 1915), derivadas del sistema de financiación que puede dar lugar a conflictos («una y/u otra Administración») 89, con consecuencias negativas para la pronta ejecución de las obras.

87 Muy recientemente se ha aprobado la ley 14/1992, de 28 de diciembre, de patrimonio agrario de la Comunidad Autónoma de Aragón y de medidas específicas de reforma y de. sarrollo agrario (Boletín Oficial de Aragón, núm. 2, de 8 de enero de 1993), que reabsorbe el contenido de la Ley el Patrimonio Agrario de Aragón de 1991, adaptándola en sus aspectos organizativos y ampliando el objeto de la misma. Recuerdese que, la ley del Patrimonio y su antecedente, la Ley del Banco de Tierras, tuvieron como finalidad casi exclusiva dar respuesta a la expropiación de bienes comunales y patrimoniales municipales afectados por las grandes operaciones de transformación en regadío.

88 En ejercicio de sus competencias estatutarias, por D. 14/1987, de 16 de febrero, la Diputación general de Aragón, declara de interés nacional (debiera haberse calificado como "regional», pues el interés "nacional» lo declara el Gobierno de la Nación), la mejora de los regadíos existentes en la cuenca del río Huecha (Zaragoza).

89 En relación con los planes pendientes de ejecución se han aprobado, tanto por el Consejo de Ministros como por la Diputación General de Aragón, varios Decretos relativos a Bárdenas II, Calanda-Alcañiz, Monegros, $2^{\mathrm{a}}$ Parte, $1^{\mathrm{a}}$ Parte, $2^{\mathrm{a}}$ Fase y Monegros IV, $1^{\mathrm{a}}$ 
El Gobierno aragonés ha regulada la concesión de distintas ayudas con destino a la transformación y mejora de los regadíos, tanto en relación con actuaciones en zonas de riegos declaradas de interés nacional ${ }^{90}$, como en el resto del territorio aragonés ${ }^{91}$.

En cuanto a la problemática particular del sistema de Riegos del Alto Aragón, debe tenerse presente que la STS de 20 de enero de 1989, Arz. 144, en el recurso presentado por la Comunidad General de Riegos del Alto Aragón contra el R.D. 2473/1985, de 27 de diciembre, por el que se aprobó la tabla de vigencias a resultas de la LAg 1985, declaró vigente la ley de 7 de enero de 1915, «en cuanto afectó o destinó caudales de los ríos Gállego, Cinca, Aztón y Guatizalema al riego de las zonas de Sobrarbe, Somontano y Monegros", esto es, en cuanto que dicha ley estableció una reserva de caudales para el riego de esas comarcas, que constituye un verdadero título de aprovechamiento y no una simple expectativa. La importancia que dicho fallo tiene además de constituir una verdadera reserva de caudales para riegos, no está tanto en la eficacia que pueda tener para vincular las futuras Leyes de Presupuestos del Estado (muy escasa si no hay voluntad política de satisfacer esa deuda histórica con Aragón), sino sobre todo en las ventajas que puedan derivarse del sistema de auxilios a las obras previstos en el bloque normativo de Riegos del Alto Aragón en comparación con el sistema derivado de la LAg. 1985 y su desarrollo reglamentario (art. 106 y D.T. $8^{\mathrm{a}}$ LAg. y art. $\left.300 \mathrm{RDPH}\right)$.

Parte (Sector I), en relación con las cuales se aprueba los correspondientes Planes Coordinados de obras. En todos estos Decretos, en relación a la financiación, las obras de infraestructura hidráulica corresponde al MOPT y las obras de transformación a la Diputación General de Aragón. Los problemas relativos a la financiación a los que se alude en el texto se refiere, sobre todo, a las actuaciones futuras para culminar lo que aun queda pendiente.

90 Así por ejemplo los Decretos $154 / 1988$, de 4 de octubre, por el que se autoriza a formalizar Convenios con los propietarios de explotaciones agrarias radicadas en las zonas regables de interés nacional en Aragón; 108/1989, de 17 de agosto, por el que se establecen medidas de apoyo a las iniciativas privadas destinadas a la sistematización, equipamiento y mejora de las estructuras de regadío en las zonas regables de interés nacional y de concentración parcelaria.

91 Así por ejemplo los Decretos 136/1988, de 19 ed julio para actuaciones en las Zonas Agrícolas Desfavorecidas en Aragón incluidas en la Directiva CEE 86/466, mediante la realización de obras de mejora de las redes colectivas de irrigación y drenaje existentes, y se procede a la declaración de las mismas como obras de interés general; 109/1989, de 17 ed agosto, por el que se establecen ayudas para obras de mejora y creación de las infraestructuras básicas de regadío (40\% en áreas comprendidas dentro del objetivo 5 b definido en el Reglamento 2.052/88 CEE) o 30\% de subvención del proyecto, en los restantes casos), texto desarrollado por la Orden de 22 de septiembre de 1989. El problema que plantean estos Decretos de financiación no es otro que el de la dotación presupuestaria (siempre insuficiente), destinada a dichos fines. 
COMPETENCLAS EN MATERIA DE AGUAS

\section{2) Navarra}

Importante es la legislación navarra en materia de financiación agraria, entre cuyos objetivos incluye la implantación de nuevos regadíos y la mejora de los existentes, aspecto particular contemplado en el Título III 92 del Decreto Foral Legislativo 133/1991, de 4 de abril, por el que se aprueba el texto refundido de las disposiciones de rango legal sobre financiación agraria.

Destaca tanto la amplitud de las inversiones objeto de subvención, siempre que hayan sido declarados de interés especial por el Gobierno de Navarra (nuevos regadíos tanto en terrenos de propiedad particular como en comunales, mejora de los existentes) como, sobre todo, la cuantía de los beneficios, que varían según la clase de inversión. Las obras de instalación primaria en nuevos regadíos, 50\% a fondo perdido, restante $50 \%$ préstamo a reintegrar en 25 años, 5 de ellos de carencia, a un interés del $2,5 \%$ anual y anualidad constante. Las instalaciones fijas en parcelas que se realicen en terrenos comunales de nuevos regadíos: $75 \%$ a fondo perdido, $25 \%$ préstamo, a 20 años, 1 de ellos de carencia, al $7 \%$ de interés anual, y anualidad constante. Las instalaciones en parcelas que se realicen en terreno de propiedad privada: $20 \%$ a fondo perdido y $80 \%$ subvención de 7 puntos de interés por plazo no superior a 20 años, en los prestamos o créditos obtenidos. Mejora de regadíos en zonas de concentración parcelaria: $50 \%$ a fondo perdido, $50 \%$ préstamo a 25 años, 5 de carencia, 2 '5\% interés anual y anualidad constante.

Pueden ser beneficiarios los Ayuntamientos, Concejos y demás entidades administrativas de Navarra, agricultores que presenten sus solicitudes a través de Comunidades de Regantes o Sindicatos de riegos (art. 8). El límite de la superficie a subvencionar es la de $15 \mathrm{Has}$, salvo en el caso de terrenos comunales para los que no existe limitación. Si la superficie a transformar se encuentra en una zona de transformación cuya extensión en su conjunto es superior a $1000 \mathrm{Has}$, el sistema de financiación será el previsto en el Título III del Libro III de la Ley de Reforma y Desarrollo Agrario.

92 El D. Foral 283/1988, de 30 de noviembre, desarrolló reglamentariamente la ley 6/1988, ed 7 de noviembre, de modificación del Título III de la ley $8 / 1985$ de 30 de abril, de Financiación Agraria. Debe tenerse en cuenta que, salvo el art. 7.d), que fue modificado por la ley 7/1991, de 26 de febrero, el contenido de este título tras la refundición es prácticamente idéntico al de la ley 6/1988. Por ello, conserva plena vigencia el D. Foral $283 / 1988$, de 30 de noviembre, salvo su artículo 4, d) afectado por la nueva redacción del art. 7. d) del Decreto Foral Legislativo. 


\section{MEDIO AMBIENTE}

El «medio ambiente» 93 , constituye un título competencial de una importancia extraordinaria por varios razones. En primer lugar, porque el agua, como recurso natural, es uno de los elemento esenciales que entran en la definición del medio ambiente. En segundo lugar, porque el "medio ambiente» constituye en realidad un supraconcepto que engloba otros "subtítulos" (espacios naturales, protección de la flora y de la fauna, vertidos contaminantes). En tercer lugar, porque la Ley de Aguas de 1985 reconoce una posición privilegiada a cuantas medidas se dicten en aplicación de la legislación ambiental y de protección de la naturale$\mathrm{za}$, que afecten a los recursos hídricos, de modo que dichas medidas deben recogerse y vinculan a los Planes Hidrológicos (art. 41.2 LAg) ${ }^{94}$.

Esta última razón constituye la mejor prueba de la importancia que puede tener para las Comunidades Autónomas el ejercicio de este título competencial. Puedo adelantar que gracias a él las Comunidades Autónomas que no tienen competencias en relación con la gestión de los recursos y aprovechamientos hidráulicos (disposición del agua) en las cuencas intercomunitarias pueden tenerla de una manera indirecta (las más de las veces una competencia negativa, obstructiva de la competencia del Organismo de cuenca, esto es, impidiendo que se disponga de recursos hídricos expresamente protegidos), en virtud de este título. Es preciso advertir en todo caso que no valen los planteamientos generales o abstractos y que ha de estarse al caso concreto, a la previsión específica para resolver de qué manera incide en los títulos específicos relativos a recursos y aprovechamientos hidráulicos, desplazándolos llegado el caso.

El mayor problema estriba en que no todas las Comunidades Autónomas tienen, en principio, el mismo techo competencial en materia de medio ambiente. Las del $143 \mathrm{CE}$ sólo tienen para la ejecución de la legislación del Estado. Las del 151 o en el caso especial de Navarra, pueden además de desarrollar la legislación básica estatal, establecer normas adicionales de protección (art. 149.1.23 $\mathrm{CE}$ ). No obstante, las

\footnotetext{
93 Sobre el concepto de medio ambiente y la distribución de competencias Estado-Comunidades Autónomas, véase el libro de J. DOMPER FERRANDO, El medio ambiente y la intervención administrativa en las actividades clasificadas, Cívitas-Universidad de Zaragoza, 2 vols., Madrid, 1992.

94 Según dicho precepto "podrán ser declarados de protección especial determinadas zonas, cuencas o tramos de cuencas, acuiferos o masas de agua por sus características naturales o interés ecológico, de acuerdo con la legislación ambiental y de protección de la naturaleza. Los Planes Hidrológicos recogerán la clasificación de dichas zonas y las condiciones específicas para su protección".
} 
referidas diferencias parecen limadas en la jurisprudencia constitucional, en particular a partir de la STC 170/1989, de 19 de octubre, caso del Parque Regional de la Cuenca Alta del Manzanares, siempre que se respete la legislación básica del Estado ${ }^{95}$.

Vamos por ello a analizar los distintos subtítulos que engloba el supraconcepto «medio ambiente».

\section{1) Protección de la flora y de la fauna: caso de Navarra}

La riqueza piscícola existente en aguas continentales (aunque en sí misma no es un bien de dominio público, sino una res nullius que se adquiere por ocupación en las condiciones legales y reglamentarias vigentes) 96 , ha sido objeto, de siempre, de específica protección. Hoy su régimen jurídico específico al que remite el art. $48.3 \mathrm{LAg}$, está recogido por la ley 4/1989, de 27 de marzo, de conservación de los espacios naturales y de la flora y fauna silvestres y por la ley de 20 de febrero de 1942 , de fomento y conservación de la pesca fluvial, sin olvidar la que han podido dictar las Comunidades Autónomas, en desarrollo de las competencias en materia de pesca en aguas continentales.

No voy a entrar ahora en la exposición de esta por lo demás, importante temática. Unicamente quiero destacar que, como consecuencia de sus competencias en la materia, bien en aplicación de las técnicas de protección previstas en la legislación básica estatal o de la propia, las Comunidades Autónomas pueden dictar medidas de protección de la fauna y de la riqueza piscícola, garantizando que discurran determinados caudales por los ríos.

Esta es la finalidad de D. Foral 344/1990, de 20 de diciembre, por el que se determinan los aspectos ambientales que deberán contemplar los proyectos de instalaciones de pequeñas centrales hidroeléctricas y se establecen conjuntamente con otras medidas de protección del medio ambiente, los caudales mínimos a respetar en los cauces fluviales afectados. Prohíbe el emplazamiento de nuevas centrales en zonas declaradas como Reservas Integrales y Naturales o como Enclaves

95 En todo caso, en materia de protección de medio ambiente en relación con los recur-
sos naturales (la ribera del mar) la STC 149/1991, de 4 de julio, recoge una interpretación
ampliatoria de las competencias que puede ejercer el Estado en la materia (no limitadas
solo a lo básico) en cuanto que uel deber estatal de dejar un margen de desarrollo de la
legislación básica por la normativa autonómica es menor que en otros ámbitos (F.J. 1.D).

96 Art. 37 de la Ley de fomento y conservación de la pesca fluvial de 1942. 
naturales o constituyan reductos de especies de fauna y flora catalogadas como en peligro de extinción o sensibles a la alteración de su hábitat (art.3); establece unos caudales mínimos a respetar para garantizar la vida de las diversas especies piscícolas (art.4); y fija medidas técnicas relativas a la construcción de las nuevas centrales para permitir la movilidad de las especies ${ }^{97}$.

\section{2) Espacios naturales}

La competencia sobre espacios naturales constituye otro de los subtítulos que engloba el concepto de medio ambiente (STC 170/1989, de 19 de octubre), por más que, como ha señalado la doctrina 98 , pueda vincularse con otros títulos competenciales (ordenación del territorio, agricultura, ganadería, pesca y caza, montes, turismo). La mayor dificultad para justificar las competencias de las Comunidades Autónomas en esta materia puede derivar del distinto techo competencial que tienen éstas en materia de medio ambiente y al que ha he hecho referencia (sólo gestión en materia de protección o competencias de desarrollo incluido la de dictar normas adicionales de control).

Los diferentes techos competenciales sobre medio ambiente, al que he aludido, quedan relativizados al haber asumido todas las Comunidades Autónomas las competencias sobre espacios naturales, advirtiéndose una notable evolución en la jurisprudencia constitucional respecto su rígida posición inicial.

La ley 4/1989, de 27 de marzo de conservación de los espacios naturales y de la flora y fauna silvestres, algunos de cuyos preceptos tienen la consideración de básicos, tiene por objeto la protección, conservación,

\footnotetext{
97 Cabe preguntarse si, pese a esta posición prevalente de las medidas de protección medio ambiental, que en este caso llevan a obstaculizar la instalación de centrales hidroeléctricas, llegado el caso primarían estas medidas protectoras o las necesidades derivadas del Plan estratégico nacional en materia de producción de energía eléctrica. El tiempo transcurrido desde que se escribió este trabajo me permite al corregir pruebas rectificar los planteamientos que figuran en el texto en relación a los caudales mínimos. Su fijación corresponde a la Administración Hidraúlica competente. Las Comunidades Autónomas pueden declarar los espacios protegidos pero la disposición del recurso (agua) no les corresponde. Este es el criterio que sigue el art. 35 del Anteproyecto de Plan Hidrológico Nacional. Véase mi trabajo «La Administración Hidráulica en el Plan Hidrológico Nacional».
}

98 En cuanto a la justificación de la competencia regional, véase por todos el comentario de LOPEZ RAMON al art. 35.1.10 del Estatuto de Aragón, en Comentarios al Estatuto de Autonomía de la Comunidad Autónoma de Aragón, vol. col. dirigido por J. BERMEJO VERA, IEAL, Madrid, 1984, pp. 389-390. 
restauración y mejora de los recursos naturales (entre los que ha incluirse el agua) y en particular lo relativo a espacios naturales. Dos son los instrumentos previstos, cuyo desarrollo legislativo encomienda a las Comunidades Autónomas: la figura de los Planes de Ordenación de los Recursos Naturales (art. 4) y la posible clasificación de los espacios naturales en alguna de las categorías previstas en la ley (Parques, Reservas Naturales, Monumentos Naturales y Paisajes Protegidos, arts. 12 y ss.) u otras diferentes que pueden establecer las Comunidades con competencias para dictar normas adicionales de protección (art. 21.2). La declaración de un espacio como Parque o Reserva natural exige la previa aprobación del correspondiente Plan de Ordenación de los Recursos Naturales (art. 15.1), salvo que por existan razones excepcionales que lo justifiquen, en cuyo caso el Plan se aprueba con posterioridad a la declaración (art. 15.2).

a) Aragón

En el marco de esta legislación básica, Aragón ha aprobado la ley $2 / 1990$ de 21 de marzo, de declaración de monumentos naturales de los Glaciares Pirenaicos ${ }^{99}$ y la ley 5/1991, de 8 de abril, de declaración de la reserva natural de los Galachos de la Alfranca de Pastriz, la Cartuja y el Burgo de Ebro (zona húmeda y típico soto o bosque ribereño junto al Ebro, próximo a la capital aragonesa). Esta declaración se realiza sin previo Plan de Ordenación, como permite el art. 15.2 ley de 1989, pero el art. 8.1 de la ley aragonesa recoge, entre otras normas de protección, sin perjuicio de las que se establezcan en el correspondiente Plan, las dos siguientes prohibiciones:

«m) Desecar las areas húmedas naturales.

n) Extraer agua de los galachos, sin periuicio de contemplar las autorizaciones otorgadas con anterioridad a la aprobacion de esta ley".

He aquí, como una norma de protección de una Reserva natural (una zona húmeda en sí misma considerada, como se deduce del art. $41.2 \mathrm{LAg}$ ) incluye la prohibición de desecar y la de extraer agua (competencia que he llamado «negativa» sobre el recurso), como medida necesaria para la conservación de dicho espacio natural y que el Plan Hidrológico del Ebro deberá tener en consideración. Obsérvese, que el apartado $\mathrm{n}$ ) parece respetar las autorizaciones (concesiones

\footnotetext{
99 Según el art. 3 «En las áreas protegidas de los glaciares y en las correspondientes zonas periféricas de protección queda prohibida toda actividad que de forma continua o esporádica produzca o tienda a producir cambios geológicos o que pueda alterar la dinámica del ecosistema de forma irreversible».
} 
competencia de la Confederación Hidrográfica del Ebro) otorgadas con anterioridad $¿$ Quid si dichos aprovechamientos ponen en peligro la existencia del espacio natural protegido? Por lo demás la prohibición de extraer agua ha de estimarse absoluta pro futuro, a menos que se demostrase una alteración de las circunstancias que han llevado a la declaración de protección, circunstancias que ha de valorar la Comunidad Autónoma.

\section{b) La Rioja}

Otro ejemplo de la virtualidad del título competencial medio ambiente en relación con los espacios protegidos es la que nos ofrece el Plan Especial de protección del medio ambiente natural de La Rioja y de las normas urbanísticas Regionales, aprobado por Resolución 100 del Consejero de Ordenación del Territorio y Medio Ambiente de 28 de junio de 1988. En primer lugar, nótese que se utiliza la figura del Plan Especial previsto en el art. 17 LS 1976, instrumento de planeamiento urbanístico que sirve correctamente a esa finalidad protectora del medio ambiente (protección del paisaje, conservación del medio rural en determinados lugares) 101.

Este Plan Especial de La Rioja contiene normas específicas para la protección de cauces, riberas, márgenes, embalses, aguas subterráneas, vertidos, estableciendo determinadas prohibiciones vinculadas con la utilización del suelo. Constituye una normativa formalmente urbanística pero con una finalidad esencialmente medioambiental. Además recoge

\footnotetext{
100 Sin duda, causa cierta insatisfacción el escaso rango de esta disposición por la que se aprueba el Plan Especial, dadas la evidentes limitaciones que conlleva actividades y utilización del suelo protegido.

101 Sobre la figura de los Planes Especiales véase GARCIA DE ENTERRIA-PAREJO ALFONSO, Lecciones de Derecho Urbanístico, Cívitas, Madrid, 1981 pp. 317 y ss.; recientemente A. EMBID IRUJO, "Los Planes Especiales. Régimen jurídico general», REDA, 70 (1991), pp. 169-199. En cuanto a la utilización de la figura de los Planes Especiales para proteger espacios naturales. M. BASSOLS COMA, "La protección de los espacios naturales a través de Planes Especiales de urbanismon Revista Jurídica de Cataluña, 3 (1988), pp. 111 y ss. Téngase en cuenta, además, que la fecha de este Plan Especial de La Rioja es anterior a la ley $4 / 1989$, de 27 de marzo de conservación de los espacios naturales y de la flora y fauna silvestres. Por supuesto que las medidas contempladas en este ley son más específicas que las previstas en la legislación urbanística, pero no hay incompatibilidad entre ellas. Pese a su consideración formal como instrumento urbanístico, en realidad se trata de un instrumento de protección del medio ambiente por lo que en las relaciones con la planificación hidrológica debe estarse a lo dispuesto en el art. 41.2 y no al $41.3 \mathrm{LAg}$.
} 
COMPETENCLAS EN MATERIA DE AGUAS

normas particulares para la protección específica de los espacios de catálogo 102 (enclaves de excepcional vegetación de ribera, riberas de interés recreativo, complejos de vegetación de ribera, huertas tradicionales, entornos de embalses de interés recreativo, zonas húmedas), estableciendo el régimen de dichas actividades y los usos del suelo permitidos en ellos.

\section{3) Protección de la calidad de las aguas. Vertidos de aguas resi- duales: legislación navarra}

He señalado al inicio de este trabajo que al Estado corresponde establecer el régimen de protección de los bienes del dominio público hidráulico (derivada de la titularidad estatal de dicho dominio), pero ya advertía que ello no excluía la posible participación de las Comunidades Autónomas en virtud de otros títulos competenciales sectoriales (competencias en relación con la protección del medio ambiente, la ordenación del territorio, sanidad, etc), como expresamente ha admitido la STC 227/1988, de 29 de noviembre, F.J. 20 letra e) en relación con el art. 40, g) y F.j. 25 en el que declara inconstitucional el art. 88.1 LAg por violación de las "potestades que todas las Comunidades Autónomas han asumido sobre la ordenación del territorio y la gestión del medio ambiente»).

Estas consideraciones de principio deben tenerse en cuenta como fundamento de la diversa normativa sectorial de las Comunidades Autónomas estudiadas, que podemos calificar como medidas de protección de la calidad de las aguas (vertido de aguas residuales, calidad de las aguas de baño y de las aguas potables de consumo público, aunque estas dos últimas constituyen un título específico sanidad-razón por la que se estudian en epígrafe aparte.

El vertido de aguas residuales afecta al régimen de protección del dominio público (de su calidad) competencia del Estado en todo tipo de cuencas. En las intercomunitarias, las funciones ejecutivas (la autorización administrativa de vertidos y la creación y recaudación del canon de vertidos, sin perjuicio de lo que se dirá más adelante) es competencia del Estado, y por él de los Organismos de Cuenca 103. Ello no quiere decir que esté excluida la intervención de las Comunidades Autónomas

102 Adviértase que este catálogo es específico del Plan Especial de La Rioja y que no tiene correlación con las categorías de espacios naturales previstas en el art. 12 Ley de 27 de marzo de 1989.

103 Por supuesto en que aquellas Comunidades Autónomas con cuencas intracomunitarias les corresponden dichas facultades ejecutivas. 
en esta materia (desarrollo legislativo y ejecución medio ambiente en el marco de la legislación básica estatal), en cuanto a dictar las medidas oportunas para hacer efectiva la protección del dominio público hidráulico, en especial en cuanto hace relación con las obras de ingeniería sanitaria tradicionalmente de competencia municipal, tanto en sus aspectos técnicos como financieros. Esta es la finalidad de la legislación navarra sobre saneamiento de las aguas residuales, cuya norma de cabecera es la Ley Foral 10/1988, de 29 de diciembre 104.

Como quiera que la protección de la calidad de las aguas depende de la efectiva implantación de los servicios de depuración de aguas residuales, servicio de competencia municipal (según la legislación de régimen local, art. 25.2.1 LBRL), la ley citada tiene por objeto garantizar de forma coordinada entre el Gobierno de Navarra y las Entidades locales, la evacuación a través de la red de Colectores Generales, el tratamiento y recuperación de las aguas residuales vertidas en el ámbito territorial de la Comunidad Foral (art. 1),

A estos efectos la ley distingue tres aspectos: a) la construcción de los colectores y estaciones depuradoras; b) la gestión y explotación posterior del servicio y c) el régimen financiero necesario para ejecutar dichas inversiones.

La ley encomienda la construcción de los colectores y de las depuradoras, así como su gestión a las Entidades locales, bien directamente (art. 4.2) o por sustitución (art. 4.3 y art. 9 del Reglamento), pero de conformidad con las previsiones de los Planes Directores 105 correspondientes cuya aprobación, así como la de los proyectos técnicos, compete al Gobierno de Navarra.

La ley encomienda a una empresa pública regional (Navarra de Infraestructuras, S.A.), en cuyo Consejo de Administración están representadas las Entidades locales de Navarra, la realización de las obras necesarias y la gestión de los servicios de depuración.

104 Su reglamento ha sido aprobado por D.F. 82/1990, de 5 de abril. Téngase en cuenta, además, el D.F. 55/1990, de 15 de marzo, por el que se establecen limitaciones al vertido de aguas residuales a colectores públicos.

105 El Plan Director formula el esquema y directrices básicas de saneamiento, estableciendo los diferentes ámbitos temporales y espaciales de las actuaciones necesarias (art. 2. a); define las obras y servicios de ámbito local y supramunicipal (art. 3. b y c). El Plan Trienal de Infraestructura Locales, aprobado por la Ley Foral 9/1988, de 19 de diciembre, incluye en el mismo, entre otros, el Plan de Depuración y Saneamiento. Para asegurar el cumplimiento de las directrices del Plan Director de Saneamiento debe aprobarse un Plan anual en el que se determinarán las diversas actuaciones a ejecutar en el ejercicio (art. 4 Reglamento). 
COMPETENCIAS EN MATERIA DE AGUAS

Las importantes actuaciones inversoras a que obliga la ley se financian mediante transferencias de capital de los Presupuestos de la Comunidad y con la recaudación del canon de saneamiento 106, que constituye un recurso finalista de la Hacienda Pública Navarra. La ley regula el hecho imponible, los sujetos obligados al pago, la base del canon, las tarifas, el ente perceptor, su incompatibilidad con la imposición de contribuciones especiales, estableciendo un período de implantación progresiva de las tarifas hasta su aplicación íntegra en 1992.

\section{SANIDAD}

Constituye un título específico que juega con carácter prevalente sobre otros (medio ambiente). A resultas del mismo, las Comunidades Autónomas tienen competencias para dictar normas relativas a calidad de aguas, en desarrollo de las básicas que pueda dictar el Estado, cuya finalidad es la protección de la salud de las personas.

\section{a) Calidad de las aguas de baño}

El título específico habilitante de este grupo de normas es la "sanidad" (protección de la salud física de las personas que puede verse alterada como consecuencia de la inadecuada pureza de las aguas). En este supuesto se integran las normas dictadas por Navarra 107, Aragón 108 y La Rioja 109, con características comunes muy notables. En ellas se regulan las características técnicas de las piscinas (seguridad y sanidad de las personas), el régimen de autorización e inspección de tales establecimientos así como las condiciones de calidad de tales aguas.

\footnotetext{
106 El canon de vertidos previsto en el art. $105 \mathrm{LAg}$, competencia del Estado, no impide que Comunidades Autónomas o las Corporaciones Locales puedan establecer otras cargas o figuras impositivas para financiar planes o programas públicos de depuración de aguas residuales, en cuyo caso el importe de tales cargas (caso del canon de saneamiento de Navarra) se deducirá del importe del canon de vertidos.
}

107 D.F. 100/1987, de 30 de abril sobre normas sanitarias de obligado cumplimiento en piscinas de uso público.

108 D. 87/1987, de 17 de junio, por el que se regulan las condiciones higiénico-sanitarias de las piscinas de uso público.

109 D. 79/1990, de 26 de julio, por el que se aprueba el Reglamento sanitario de piscinas de uso colectivo. 


\section{b) Aguas potables de consumo público}

También aquí el título que justifica la competencia de las Comunidades Autónomas es la protección de la salud pública mediante el control adecuado de las aguas destinadas al consumo humano (STC 208/1991, de 31 de octubre, relativa a los métodos de medición y análisis de aguas superficiales dedicadas a la producción de agua potable).

Este sentido tiene, para La Rioja, la Orden de 22 de mayo de 1987, que regula el control sanitario de los abastecimientos de agua potable (deber de crear un servicio de control y vigilancia permanente responsabilidad de los Ayuntamientos, sin perjuicio de la creación de la coordinación de dichos servicios a través del Laboratorio Regional de Salud Pública). En Navarra, el D.F. 231/1986, de 31 de octubre ha establecido una red de centros de vigilancia sanitaria de las aguas potables de consumo público, que comprende tanto los dependientes de la Comunidad Foral como los de las Entidades Locales, siendo, en todo caso, los Ayuntamientos y concejos, los responsables de las instalaciones de abastecimiento de aguas potables de consumo humano y de su control sanitario que pueden tener dichos servicios concertados o mancomunados. La Red de Centros de Vigilancia sanitaria agrupa un Centro Regional de recepción y elaboración de datos, un Centro de Análisis y Centros de Control.

\section{ORDENACION DEL TERRITORIO Y URBANISMO}

La competencia sobre ordenación del territorio y urbanismo corresponde a las Comunidades Autónomas (art. 148.1.3 ${ }^{\mathrm{a}} \mathrm{CE}$ ). La STC $227 / 1988$ de 29 de noviembre, reitera en diversos fundamentos jurídicos que las competencias que corresponden al Estado en materia de recursos y aprovechamientos hidráulicos deben respetar las competencias asumidas por todas las Comunidades Autónomas en materia de ordenación territorial y urbanismo, razón por la que considera inconstitucional por ejemplo el art. 88.1 LAg (F.J. 25), e interpreta de conformidad a la Constitución algunos preceptos que, de otra manera chocan con las competencias regionales (por ejemplo el art. 40,j LAg en cuanto al concepto de infraestructuras básicas o el art. $41.1 \mathrm{LAg}$, en lo relativo a la reserva de terrenos necesarios para las actuaciones y obras previstas, F.J. 20.e).

Al referirme a la legislación de medio ambiente ya señalé la estrecha relación que existe entre los instrumentos de ordenación territorial y urbanística y la protección medioambiental de los recursos hídricos. Ello se observa en la normativa de ordenación territorial aprobadas 
con anterioridad a la ley 54/1989, de 27 de marzo, de conservación de los espacios naturales (Navarra 110 La Rioja 111, Aragón 112). Ante la inexistencia de las categorías de protección relativas a los espacios naturales, se echa mano de la clasificación como suelo no urbanizable para proteger determinados bienes del dominio público hidráulico o bien sujeta a autorizaciones administrativas específicas cuando no exista un instrumento de planificación adecuado. Como ejemplo de la primera técnica, véase la ley navarra de 10 de abril de 1987, en relación con los cursos fluviales, lagunas, embalses y zonas húmedas, estableciendo perímetros de protección (art. 5.6.c y 26). En cuanto a la segunda, el Decreto aragonés $85 / 1990113$, cuya D.T. señala que «en tanto se desarrolla con mayor precisión la delimitación de las áreas de Suelo Protegido, además de los terrenos incluidos en la relación, se sujetarán al trámite establecido en estas normas (evaluación de impacto ambiental): los espacios situados a menos de 200 metros del cauce de los ríos y cursos de agua y embalses o lagos en todo el territorio aragonés". O la necesidad de que los proyectos de urbanización cuenten con las oportunas autorizaciones del Organismo de Cuenca en los supuestos de captaciones de agua y vertidos o depuraciones (art. 4.2 del D. 15/1991, de 19 de febrero).

En todo caso, no debe olvidarse la prevalencia de las previsiones de la planificación hidrológica sobre los diferentes instrumentos de ordenación urbanística del territorio (art. $41.2 \mathrm{LAg}$ ) ${ }^{114}$, sin perjuicio, ya lo he advertido antes, de que ha de estarse al contenido sustantivo y no a una consideración meramente formal de los instrumentos de planeamiento, dado que en éstos puede articularse perfectamente medidas de protección medioambiental.

110 Ley Foral 12/1986, de 11 de noviembre de Ordenación del Territorio y la 6/1987, de 10 de abril, de normas urbanísticas regionales para protección y uso del territorio.

111 Ya he hecho referencia al Plan Especial de protección del medio ambiente natural de la Rioja y de las Normas Urbanísticas regionales.

112 En particular las aprobadas por los Decretos 85/1990 de 5 de junio, de medidas urgentes de protección urbanísitica en Aragón y 14/1991, de 19 de febrero, de medidas urgentes sobre garantías de urbanización en la ejecución urbanística.

113 Para una valoración de dicho Decreto véase J. OLIVAN DEL CACHO, "La impugnación de las medidas "urgentes" de protección urbanística en Aragón. Comentario sumario al Decreto 85/1990, de 5 de julio, de la Diputación General de Aragón, de próxima publicación en la $R D U$.

114 Sobre la cuestión véase EMBID IRUJO, La planificación hidrológica: régimen jurídico, Tecnos, 1991, pp. 175 y ss. 
Cabe preguntarse, por último, si no podría haberse evitado la destrucción masiva de zonas de huerta tradicional (por ejemplo la zona del ACTUR de Zaragoza asentada en una de las más ricas vegas de la margen izquierda del Ebro) desde la legislación y planteamiento urbanísticos. De futuro sería conveniente que cuando suelo clasificado como no urbanizable (rústico de regadío) se convierta en suelo urbanizable se deba seguir un trámite similar al previsto en el art. 50 LS para las zonas verdes o espacios libres (dictamen previo del Consejo de Estado), dando audiencia al Organismo de Cuenca correspondiente para determinar, en su caso, la pervivencia o forma de liberación de las cargas reales que gravan los predio afectados por la reclasificación (amortización de obras hidráulicas de regulación, etc). Dicha medida introduciría algo de racionalidad en la política de ordenación del territorio. No puede una Administración transformar tierras en regadío y otra calificar dichos suelos como urbanizables.

\section{MONTES}

La competencia regional sobre esta materia posibilita actuaciones específicas de trabajos de restauración hidrológica-forestal (caso de la ley foral 13/1990, de 31 de diciembre, de protección y desarrollo del patrimonio forestal de Navarra, art. 44.6). La STC 227/2988, de 29 de noviembre, ha considerado que los planes hidrológico-forestales que constituyen contenido obligatorio de los Planes Hidrológicos de cuenca (art. 40.h LAg) «sólo pueden incluir normas básicas que tengan por objeto la protección del medio ambiente, sin perjuicio también de las competencias que correspondan a las Comunidades Autónomas» (F.J. 20, e). 